\title{
LAS SOCIEDADES ALFARERAS TEMPRANAS DE LA CUENCA DE SANTIAGO
}

\author{
EARLY CERAMIST SOCIETIES ON THE \\ SANTIAGO BASIN
}

\author{
Lorena Sanhueza R.*, Mario Vásquez M.** y Fernanda Falabella G.*
}

\begin{abstract}
En este trabajo presentamos los resultados de las investigaciones realizadas en Chile central sobre el período Alfarero Temprano. Este estudio contempló una prospección de la cuenca de Santiago, la excavación de tres nuevos sitios y el análisis de colecciones recuperadas previamente en la zona. Los análisis fueron llevados a cabo desde una perspectiva integral, aplicando un mismo marco metodológico a todos los materiales estudiados. Además se realizó un programa de fechados que consideró tanto el refechado de sitios como la datación de los nuevos sitios excavados. Los resultados permitieron proponer un primer momento caracterizado por comunidades alfareras iniciales, vigente desde la aparición de la alfarería en la zona hasta ca. 200 d.C. En esta fecha se configuran claramente dos unidades, Llolleo y Bato, que se desarrollan en forma contemporánea hasta alrededor del 1000 d.C., ocupando este espacio de manera interdigitada. Estas unidades no sólo se diferencian a partir de sus expresiones materiales y tradiciones tecnológicas, sino también representan una orientación económica y una ideología distintas. Junto a estas dos unidades, los resultados permitieron esbozar la presencia de al menos otras dos (Chacayes y EMI/RML001), que no obstante, por la escasez de datos, no pudieron ser bien definidas.
\end{abstract}

Palabras claves: Chile central, Período Alfarero Temprano, unidades sociales, cerámica.

This paper presents the results of recent archaeological research on the Early Ceramic Period in Central Chile. The study includes results from an extensive archaeological survey in the Santiago Basin, the excavation of three domestic sites and the analysis of artifact collections from several previously excavated sites. All the archaeological materials were submitted to the same methodological approach. We can differentiate a brief initial period, from the first ceramic occurrence until ca. A.D. 200, where the few known sites can be grouped under the label "Initial Ceramic Communities". Later and until A.D. 1000, two archaeological units, Llolleo y Bato, can be clearly distinguished and characterized. Both have a similar temporal development and are distributed over the same area. These archaeological units have been equated to social groups that have different material expressions, technological traditions, economic strategies and ideologies. The most outstanding feature of this social configuration is the spatial proximity and intermingling of social entities that keep and express overtly their difference in relation to others. A few sites (Chacayes) and groups of sites (EMI/RML001), also dated to the Early Ceramic Period in this region, do not share cultural characteristics with either of these complexes leading us to believe that an even wider diversification of social groupings is probable during this period. However, these relationships cannot be assessed until more evidence is available.

Key words: Central Chile, Early Ceramic Period, social units, pottery.

La definición de un Período Alfarero Temprano (PAT) en Chile central se remonta a la década de 1960 cuando se realizaron las primeras sistematizaciones espacio-temporales derivadas de investigaciones arqueológicas en la zona (Berdichewsky 1964; Schaedel et al. 1954-56; Silva 1964). Desde esa fecha se han realizado numerosos aportes con el estudio de sitios, la caracterización de sistemas culturales y la propuesta de interpretaciones sobre el funcionamiento de estas sociedades, dentro de los cuales la definición del Complejo Llolleo (Falabella y Planella 1979) y de la Tradición Bato
(Planella y Falabella 1987) constituyen hitos importantes.

Pese al interés que plantea la comprensión de este período, la visión a nivel regional y de su variabilidad interna, ha sido limitada debido a diversos factores. Entre éstos quizá los más importantes son que la arqueología sistemática y orientada a problemas en Chile central es relativamente joven; que los marcos referenciales utilizados privilegiaban la búsqueda de homogeneidad y unidad; que hasta hace poco se carecía de estudios paleoetnobotánicos, de estudios interpretativos de

* Departamento de Antropología, Facultad de Ciencias Sociales, Universidad de Chile. Ignacio Carrera Pinto 1045, Nuñoa, Santiago, Chile. loresan@uchile.cl; ffala@entelchile.net

** Sociedad Chilena de Arqueología. Eduardo de la Barra 1384, Departamento 302. Providencia, Santiago. Chile. mariogvasquezm@hotmail.com 
fauna y había escasez de información sobre sistemas productivos líticos; que las unidades arqueológicas más consistentes (Bato-Llolleo), en tanto unidades operativas, han sido definidas a base de investigaciones en sitios costeros; y que la arqueología del interior se ha desarrollado fundamentalmente apoyada en excavaciones de rescate y sus componentes y sitios arqueológicos generalmente se han interpretado en referencia a los costeros.

Nuestro interés en este trabajo es ofrecer una visión actualizada del PAT, donde el aporte fundamental deriva de información inédita obtenida de estudios sistemáticos en el interior (cuenca de Santiago) y de la aplicación de una metodología común al análisis de los sitios más relevantes conocidos en la zona. Las investigaciones en el interior dan cuenta de componentes arqueológicos muy variados. Pero, por los motivos anteriores, existe confusión en su adscripción cultural e interpretación social. Por lo tanto un aspecto importante de nuestro estudio ha sido encarar la investigación con un enfoque que reconoce la variabilidad en todas las instancias, desde el trabajo de campo hasta los análisis y la interpretación de los datos.

Creemos que es posible, en este momento, sistematizar los datos disponibles de la realidad en la cuenca de Santiago e integrarla en una perspectiva areal a nivel de Chile central. Para ello es necesario hacer uso de "unidades" ordenadoras que organicen los datos de acuerdo a criterios de similitud y diferencia. Proponemos organizar los contextos en función de un número de unidades arqueológicas que implican la creación de conjuntos nuevos y el manejo de unidades tradicionalmente utilizadas para la prehistoria del PAT de Chile central. En este último caso, se hace una reevaluación de los criterios definitorios de dichas entidades.

\section{Las Unidades Operacionales y su Historia}

A fines de la década de 1970 y comienzos de la década de 1980 se propuso un ordenamiento del registro arqueológico de Chile central definiendo dos amplias unidades culturales, denominadas Complejo Llolleo (Falabella y Planella 1979) y Tradición Bato (Planella y Falabella 1987). Esto se realizó enteramente sobre la base de investigaciones en sitios de la costa. En el caso Llolleo, la excavación en tres sitios habitacionales de la zona de desembocadura del río Maipo, Tejas Verdes, Rayonhil y Santo Domingo 2, permitieron recono- cer un componente cultural cuya cerámica era similar a la rescatada en otras localidades costeras tales como el cementerio de Llolleo (Oyarzún 1979 [1910]) y el fundo El Peral (colección Calvo Larraín del Museo Nacional de Historia Natural) y cuya dispersión quedó definida entre el río Aconcagua y el Cachapoal. En el caso Bato, el contexto excavado en el sitio Arévalo 2 (localidad de San Antonio) permitió integrar en un componente cultural una serie de sitios reconocidos por el equipo de B. Berdichewsky, la Sociedad Arqueológica de Santiago, del Centro de Estudios Antropológicos de la U. de Chile y de la Sociedad Francisco Fonck de Viña del Mar, esto a través de las escasas publicaciones disponibles y los materiales que aún quedaban en depósitos (Planella y Falabella 1987). La dispersión de esta tradición quedó definida desde Longotoma por el norte, hasta San Antonio (desembocadura río Maipo) por el sur.

Si bien toda esta información provenía de sitios costeros, también existían antecedentes en el interior que evidenciaban materiales culturales semejantes a los del litoral.

En el caso del Complejo Llolleo se trataba de piezas cerámicas aisladas o asociadas a otras, que en general provenían de entierros. Esto permitió reconocer contextos de "ofrendas funerarias" similares a las encontradas en la costa, desde el valle del río Aconcagua por el norte hasta Lontué (cercano al río Mataquito) por el sur, lo que llevó a generar la hipótesis de un Complejo Llolleo que abarcaba prácticamente toda la zona central. Lo que aquí interesa destacar es que en ese entonces no se disponía de ningún sitio habitacional excavado en el interior que fuera comparable a los sitios habitacionales Llolleo costeros, y que los datos sobre contextos de funebria se limitaban a las ofrendas y escasas asociaciones contextuales (a nivel de tumba o sitio). Por lo tanto la construcción de la hipótesis Llolleo como unidad regional/areal se basó en el supuesto que las ofrendas funerarias semejantes implicaban un contexto cultural global también semejante. Por cierto, al no disponer de más antecedentes en esa época, dicha hipótesis era una alternativa válida.

En el caso de la Tradición Bato la situación fue más compleja. Los sitios excavados (de la costa) presentaban mayor diversidad que los Llolleo ${ }^{1}$, y lo que se reconoció para el litoral fue la asociación reiterada de ciertos patrones morfológicos (v. gr. presencia de vasijas sin quiebres abruptos en 
sus perfiles, presencia de asas mamelonares) y decorativos de la cerámica (inciso lineal punteado, pintura roja gruesa en bandas, diseños negativos, pintura roja, hierro oligisto), junto al tembetá discoidal con aletas de cerámica y/o piedra, adornos de concha, entierros sin ofrendas cerámicas y la ausencia de muchas de las características propias de los sitios Llolleo. Al comparar estos contextos Bato con evidencias del interior, se advirtió que sí existían sitios excavados donde aparecían algunos de los elementos mencionados, pero no siempre en las mismas asociaciones contextuales. Era el caso de la mayoría de los sitios clásicos estudiados hacia fines de los años setenta, como Radio Estación Naval (REN), Parque La Quintrala (PQL) (ambos en la cuenca de Santiago), Chiñigüe (curso medio del río Maipo), Chacayes (CHY) (curso superior del río Maipo) y los aleros El Salitral y El Carrizo en Chacabuco y El Arrayán y Novillo Muerto en la precordillera de Santiago. Dada la diversidad de situaciones culturales y el lapso de más de 1000 años en que aparecían estos elementos en la zona, no se planteó como una cultura o complejo cultural regional sino como una "tradición" en el uso de determinados materiales en esta región (Planella y Falabella 1987).

A fines de los años ochenta se acuñaron los conceptos de "comunidades iniciales", "comunidades mixtas" (Falabella y Stehberg 1989) y "tradición interior” (Falabella y Planella 1988-89), como un intento por sistematizar, en grandes unidades areales, evidencias de sitios aislados de los valles del interior que eran muy dispares. El concepto "comunidades iniciales" ha sido reevaluado a la luz de nuestras investigaciones. Estas han demostrado que existen aspectos comunes a una serie de sitios de fechas muy tempranas en el PAT para los cuales esta unidad resulta operativa (Sanhueza y Falabella 1999-2000). En el caso de los otros conceptos, no han sido hasta ahora reevaluados ni mayormente utilizados por ausencia de investigaciones arqueológicas orientadas hacia sitios del interior.

Es así como las unidades Llolleo y Bato se constituyeron en los grandes referentes para la arqueología del PAT en Chile central y cristalizó una interpretación en el sentido que estas unidades corresponderían a los dos "grupos sociales" que ocupaban la zona durante el PAT expresando sus diferencias en la materialidad de la cultura.
En los últimos años, las investigaciones en el sitio El Mercurio (Falabella 2000; Falabella et al. 1995-96) y en el sitio La Granja (Planella et al. 1996) han permitido ampliar la visión del complejo Llolleo en Chile central con la propuesta de un componente Llolleo de valles interiores (Planella et al. 1997). El Mercurio es un sitio habitacional con un sector contiguo de enterratorios, el cual informa sobre los contextos de basura de actividades diarias y de funebria. La Granja es un sitio de características particulares, que ha sido interpretado como un lugar donde se realizaron actividades rituales, a base de la abundancia de restos de pipas, la alta proporción de fragmentos de jarro y la frecuencia de las decoraciones de esta categoría de vasija (Planella et al. 2000). La información derivada de ellos permite señalar que la similitud de los sitios que se identifican como "Llolleo", entre la costa y el interior, se desprende fundamentalmente del conjunto de vasijas utilizadas en los rituales funerarios y sociales; de aspectos de la funebria como es el uso de urnas para párvulos, posición de los individuos y las ofrendas; y del uso de adornos corporales como los collares de cuentas discoidales de piedra. Esto se ha planteado como el reflejo de los elementos identitarios de un sistema tribal que reúne comunidades y posiblemente grupos de linaje sin jerarquías permanentes (Falabella 2000). Creemos que la "homogeneidad" y consistencia de la unidad Llolleo deriva en parte del uso de un elemento altamente visible en arqueología, como es la cerámica y rituales recurrentes.

Por otro lado, a mediados de la década de 1990 Sanhueza (1997, 2000) realiza estudios de los contextos cerámicos de varias colecciones provenientes de sitios del interior (El Mercurio, Parque La Quintrala, Chacayes, Los Panales y otros aleros precordilleranos), en cuyo marco se realiza una primera sistematización de estos contextos, la que sugiere una realidad bastante compleja y diversa para el PAT de Chile central.

\section{Aproximación Metodológica}

Dado el estado del conocimiento sobre el PAT en Chile central al iniciar nuestras investigaciones, nos planteamos la necesidad de contar con mayor información sobre las ocupaciones de este período en el área de estudio (cuenca de Santiago) y que ésta reflejara la variabilidad cultural existente al interior del período. Para ello se realizó una pros- 
pección que nos permitió obtener una visión más general y acabada de la distribución espacial y diversidad de sitios, y luego seleccionar algunos de ellos para su excavación. Paralelamente, se planteó la importancia de realizar un reestudio y nuevos fechados de las colecciones de materiales existentes para este período en esta área.

Las prospecciones realizadas en la cuenca de Santiago cubrieron un $3 \%$ de su superficie prospectable $^{2}$ y permitieron el reconocimiento de 83 sitios arqueológicos y un importante número de hallazgos aislados ${ }^{3}$. De éstos, 18 tienen ocupaciones pertenecientes al PAT, 16 son bicomponentes (PAT/período Intermedio Tardío o PIT), 30 corresponden a ocupaciones Aconcagua (PIT), dos son tricomponentes (PAT/PIT/período Tardío o PT) y tres son bicomponentes (PIT/PT); además seis corresponden a época posthispana y ocho no pudieron ser asignados a algún período cultural específico, dada la ausencia de elementos diagnósticos (cerámicos o líticos). Cabe destacar, además, que no se encontraron sitios asignables al período Arcaico. Parece poco probable que esta área haya estado desocupada durante ese extenso período, por lo que creemos que las razones de no haber encontrado vestigios de las ocupaciones de esos cazadores recolectores son de índole metodológico y postdepositacionales. La prospección consistió en una revisión superficial del terreno. En su mayoría se trataba de áreas alteradas por la actividad agrícola. Dadas las magnitudes de depositación en la cuenca, que en algunos sectores es muy alta (v. gr. Lonquén: 1,5 m en 1000 años), es muy probable que algunas ocupaciones, especialmente las más tempranas, estén cubiertas por una gran acumulación de sedimentos y por lo tanto sean imposibles de detectar en superficie. Por otro lado, la acción del arado, si bien juega muchas veces a nuestro favor al exponer los materiales en superficie, también revuelve y homogeniza los materiales y por tanto obstruye el reconocimiento de las evidencias de diferentes ocupaciones, entre las que se pueden encontrar las ocupaciones Arcaicas, especialmente si sus materiales se mezclan con los de una ocupación cerámica.

En los sitios identificados como tempranos se realizaron recolecciones superficiales intensivas ${ }^{4}$ con miras a recuperar una cantidad de material que permitiera tener una idea clara respecto de las características del sitio y a partir de ellos aproximarnos a la variabilidad existente en los contextos del
PAT de la cuenca. En una primera instancia, esto aparentemente dio resultados, ya que las recolecciones de superficie analizadas evidenciaban características diferentes, e incluso era posible sugerir agrupaciones de sitios. Nuestra posterior experiencia, a partir de los tres sitios que excavamos, nos mostró que la caracterización de los sitios a base de las recolecciones de superficie no se corresponde con la obtenida de los materiales de excavación (tanto en relación a la estructura de los materiales, como a la presencia de ciertos elementos de forma o decoración de la cerámica), por lo que la variabilidad observada en las recolecciones superficiales mostró no tener valor analítico ni comparativo.

En este sentido también fue importante constatar que la dispersión de materiales en superficie no necesariamente refleja la concentración de materiales bajo ella. De esta forma nos encontramos tanto con sitios con mucho material en superficie, pero que no contaban con más de $10 \mathrm{~cm}$ de depósito, como con amplias dispersiones continuas de materiales, pero que sólo en ciertos sectores presentaban depósito. Solamente a través de la realización de pozos de sondeo pudimos evaluar adecuadamente los sitios y decidir cuáles y dónde excavar.

La revisión de las colecciones del PAT, recuperadas en décadas pasadas ya sea como rescates (v. gr. Radio Estación Naval) o como parte de programas de estudio (v. gr. proyecto Lampa), constituyó un aspecto relevante de la investigación ya que permitió ampliar significativamente la muestra, al aplicar un mismo marco metodológico de análisis a estos materiales y a aquellos obtenidos en los nuevos sitios excavados. Algunos elementos que dificultaron esta labor fueron la pérdida parcial o total de algunas colecciones (Tabla 2) y las diferencias en la resolución y técnicas de recuperación de materiales, los que afectaron especialmente los análisis líticos (por sesgo de la fracción más pequeña de las muestras) y arqueobotánicos (ausencia de restos botánicos por no aplicación de técnica específica de recuperación).

$\mathrm{El}$ factor cronológico constituye un elemento esencial en la comparación entre los sitios y la comprensión del PAT, por lo que se fecharon sitios que no contaban con determinación cronológica, y se refecharon sitios que precisaban afinar su cronología. 
Uno de los objetivos centrales de la investigación que presentamos es dar cuenta de la variabilidad cultural existente en este período. La metodología utilizada para caracterizar los componentes (u ocupaciones) del PAT en Chile central, contempló, por lo tanto, el análisis integral de todos los materiales arqueológicos de cada sitio, es decir, no solamente la cerámica y el lítico, que constituyen los materiales más abundantes, sino también los restos óseos y arqueobotánicos (para lo cual se hicieron columnas de muestreo para análisis arqueobotánico), así como los adornos personales (tembetás, cuentas) u otros objetos (v. gr. pipas).

Respecto a la cerámica optamos por un análisis integral, que apuntara a la definición del conjunto cerámico de los grupos que ocuparon los sitios, lo que supone caracterizar las vasijas de los sitios habitacionales de éstos. Por esto se realizó, además de una clasificación básica, análisis de pastas, de formas y de decoraciones, cuya integración nos permite definir en primera instancia categorías de vasijas y, en última, los conjuntos cerámicos. La cerámica (analizada de esta manera) resultó ser suficientemente sensible y nos permitió establecer similitudes y diferencias que ordenaron en cierta medida el panorama del PAT.

El estudio del material lítico fue abordado a través de una estrategia integral que combinó el estudio sistemático de desechos y microdesechos conjuntamente con el análisis tradicional de instrumentos, el cual involucró la definición de categorías instrumentales a través de criterios morfológicos, tecnológicos y funcionales. Es importante tener en cuenta que el potencial de información del material lítico fue restringido por distintos factores, entre los cuales se cuentan sesgos por la disminución y ausencia de colecciones, y problemas de muestra en sitios excavados debido a la baja densidad de instrumentos. Por otra parte, debemos destacar que el material lítico, en relación a la cerámica, presenta un nivel de resolución ostensiblemente menor para la definición de unidades arqueológicas dentro del PAT. No obstante cabe destacar que el control sistemático de microdesechos en los sitios excavados por este proyecto significó una buena aproximación a la cobertura de recursos, la funcionalidad de los sitios y la secuencia de reducción.

El análisis de los restos óseos se centró en la identificación taxonómica de las especies presentes y de los patrones de conducta asociados a su utilización. Lamentablemente las colecciones re- visadas no contaban con restos óseos, y de los sitios excavados por nosotros, sólo uno presentaba una cantidad importante de ellos. La ausencia de restos óseos de los otros sitios no es un hecho poco significativo, ya que, una vez descartada la variable conservación, se puede hipotetizar la existencia de variables culturales para explicar su ausencia (funcionalidad del sitio, patrón de subsistencia).

El análisis arqueobotánico estuvo centrado en la identificación de las especies presentes en los depósitos, para contribuir, en conjunto con los restos faunísticos, en la definición de patrones de subsistencia. En este sentido fue central no sólo la identificación de especies cultivadas sino también la variabilidad de las especies silvestres. Lamentablemente, sólo contamos con estos datos para los sitios excavados por nosotros. Además las características del depósito de uno de ellos (sólo 40 cm de profundidad) dificulta la correcta evaluación de los datos, lo que limita la posibilidad de integrar esta variable a la caracterización integral de los sitios (y el PAT en general). Sin embargo estos datos poseen un gran potencial, el cual se podrá analizar cuando se cuente con más información para las ocupaciones del PAT en la región. Respecto a los otros materiales, no sólo fue importante constatar su presencia, sino que explorar las diferencias que pudieran presentar (formales, materias primas), así como su distribución y su asociación con otros materiales del contexto.

\section{Enfoque Analítico}

Uno de los mayores problemas que se nos planteó desde el comienzo de esta investigación fue como sistematizar la enorme cantidad de datos obtenidos de cada contexto estudiado. La variabilidad advertida en los contextos nos puso en evidencia, casi desde un principio, que un enfoque tradicional, fuertemente apoyado en unos pocos elementos diagnósticos para la asignación cultural o la generación de nuevas unidades arqueológicas, no nos sería útil. Algunos de estos elementos, como por ejemplo los mamelones y ciertas decoraciones (inciso lineal punteado, inciso reticulado) de la cerámica, o los tembetás, considerados hasta ahora como 'emblemáticos' de ciertas unidades, no siempre se presentaban asociados, y cuando lo hacían, no siempre se asociaban de la misma manera en términos de sus frecuencias (Sanhueza et al. 2000). 
El análisis de un mayor número de contextos nos permitió darnos cuenta que, si bien no existían asociaciones rígidas entre ciertos elementos o rasgos, algunos de éstos sí se presentaban recurrentemente juntos y que algunas de estas asociaciones se 'oponían' a otras, en el sentido de que los elementos asociados eran excluyentes.

$\mathrm{Al}$ interior de cada una de estas asociaciones recurrentes, no obstante, observamos que existía una gran variabilidad, especialmente en términos de la importancia de cada elemento asociado. Así, se presentaba casi el mismo número de situaciones diferentes como contextos analizados. Esta situación descrita es válida, tanto al interior de cada categoría artefactual como a nivel de sitio, lo que nos llevó a considerar la configuración de las unidades en términos politéticos.

Sin duda fue el material cerámico el que permitió un ordenamiento de mayor resolución del universo estudiado, ya que, si bien en el material lítico también se presentan ciertas oposiciones, éstas lo ordenan de una manera más gruesa.

En el caso de la cerámica, la naturaleza de los elementos asociados incluye tanto técnicas de manufactura como elementos de forma y ciertas decoraciones, implicando así al conjunto cerámico en su integridad, lo que nos ha llevado a pensar que estas asociaciones son culturalmente significativas.

En el caso del material lítico, sin embargo, no se pudo reconocer o diferenciar tradiciones tecnológicas propiamente tales, pero se identificaron ciertas asociaciones recurrentes entre ciertos tipos de materiales o entre ciertas categorías morfológicas, que permitieron proponer al menos dos conjuntos que significarían formas diferentes de acercamiento al medioambiente y sus recursos, información que se vio complementada con la obtenida a partir de los estudios arqueobotánicos y faunísticos.

La variedad de situaciones observadas a partir de los análisis cerámicos y líticos por separado se multiplican al asociar ambos elementos. Esta situación, creemos, es propia de las sociedades con una organización social como ha sido propuesta para el PAT, donde la normatividad sería relativamente baja, lo que se vería reflejado en la variabilidad de las expresiones materiales de estos grupos.

En términos de producir un ordenamiento, consideramos la tecnología de producción cerámica como el elemento más relevante, debido a las ca- racterísticas propias de la producción alfarera. La alfarería en general es una artesanía de carácter tradicional, ya que la obtención de un conjunto de vasijas "culturalmente adecuadas", es decir, vasijas que puedan ser utilizadas para lo que fueron hechas, involucra un lento y largo proceso de aprendizaje acerca del comportamiento de los materiales utilizados y su relación con cada una de las etapas de manufactura y cocción (Rice 1987). De todos los conocimientos, la tecnología de preparación de las pastas es la más tradicional, ya que cualquier cambio en ella afecta de manera importante el resultado final del proceso.

La transmisión de este conocimiento, dada la ausencia de sistemas de producción más complejos en el PAT, debiera ocurrir en la unidad doméstica. De esta manera, el reconocimiento de "patrones" o "estilos" en las pastas, nos permitiría identificar líneas de transmisión de conocimiento y de relaciones sociales, que es lo que nos interesa reflejar a través de las unidades arqueológicas que construimos. Las formas y decoraciones, si bien también son parte importante de los estilos alfareros, no requieren necesariamente de este tipo de aprendizaje. Al ser visibles pueden copiarse y en ese caso no reflejarían necesariamente dichas relaciones cara a cara.

Los otros aspectos, que nos remiten a la relación de estos grupos con el medioambiente, la subsistencia, u otros aspectos de las relaciones sociales, quedan, en este enfoque, subordinados, aunque siguen siendo tomados en cuenta como un factor más de la variabilidad cultural al interior del PAT. Creemos que éstos, al igual que ciertos aspectos de la cerámica, apuntan a otro nivel de relaciones, más específico, y cuyo estudio necesita de enfoques particulares.

En nuestro proceso de análisis y de construcción de unidades arqueológicas hemos incorporado las tradicionales unidades Llolleo y Bato. Como ya vimos, estas unidades fueron propuestas en las décadas pasadas a partir de la sistematización de datos costeros principalmente, y se constituyeron rápidamente en los referentes para todos los sitios y datos nuevos de este período que surgieron con posterioridad en todo Chile central. Nuestros resultados, a partir del enfoque que hemos propuesto, nos muestran una realidad más variable y por ende más compleja en el interior. La solución a esta mayor complejidad, no obstante, no pasa por desechar estas unidades anteriores. Creemos y op- 
tamos, por el contrario, por seguir utilizando estas unidades tradicionales, pero dándoles un sentido más amplio y politético, de manera de hacerlas más coherentes con la realidad sociocultural regional del PAT ${ }^{5}$.

Creemos que esta realidad sociocultural y su consecuente expresión material, a la cual accedemos fragmentariamente para el estudio de este período, jamás nos permitirá la construcción de unidades arqueológicas homogéneas y 'cerradas'. Así, somos nosotros los que debemos adecuar nuestras herramientas a esta realidad en estudio en vez de intentar someterla a esquemas rígidos preconcebidos.

\section{Los Sitios y Materiales Analizados}

De los 36 sitios con ocupación temprana identificados en la prospección realizada (Figura 1), se seleccionaron tres para su excavación: Hospital G16/1, Lonquén E80/4 y La Palma E101/1. Los criterios de selección fueron que los sitios presentaran características diferentes a partir de análisis del material de las recolecciones superficiales, la abundancia de los materiales en general, la localización del sitio dentro de la cuenca de Santiago, la existencia de depósito y la posibilidad efectiva de realizar excavaciones, factor no menor en un área como ésta, fuertemente urbanizada e impactada por la agricultura.

El sitio Hospital G16/1, se localiza en la localidad homónima, unos $6 \mathrm{~km}$ al norte de la Angostura de Paine (UTM E 339750 N 6252700) ${ }^{6}$. Se trata de un sitio que en superficie cubre por lo menos $300.000 \mathrm{~m}^{2}$ (fue imposible delimitarlo completamente), que presenta cuatro áreas de concentración de materiales, separadas entre sí por áreas sin material en estratigrafía, las que tienen un depósito que no alcanza una profundidad mayor que $40 \mathrm{~cm}$ (excepto en dos rasgos). Asociada a una de estas concentraciones de material se encuentra un área de enterratorios, de la cual sólo se recuperó uno. Los materiales cerámicos de las cuatro áreas identificadas presentan características bastante diferentes entre sí, por lo que las interpretamos como productos de cuatro ocupaciones distintas, las que, a juzgar por los fechados, parecen ser relativamente contemporáneas (Tabla 1).

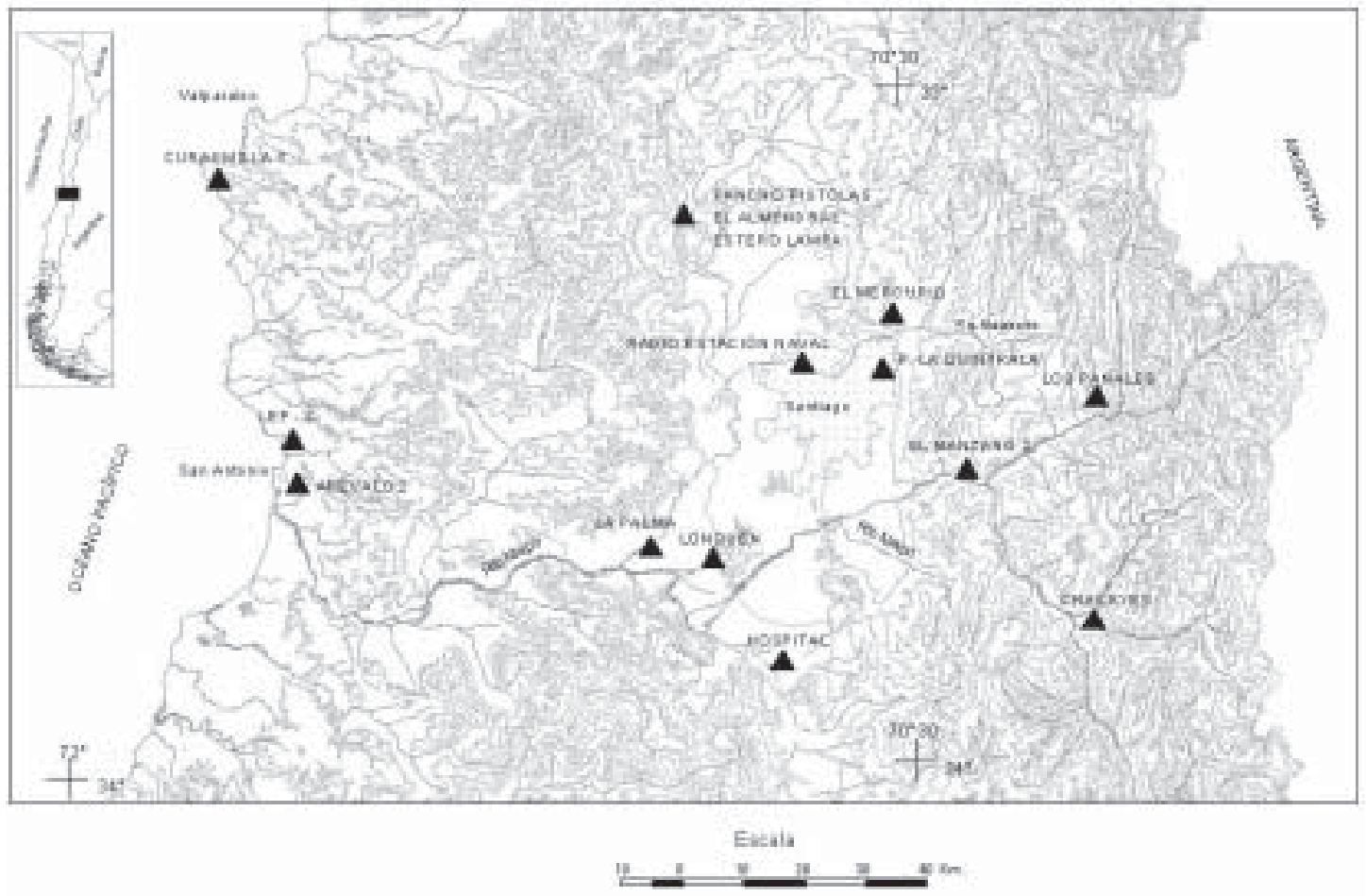

Figura 1. Ubicación de los sitios arqueológicos. Location of archaeological sites. 
Tabla 1. Fechados de radiocarbono y TL de los sitios analizados. Radiocarbon and TL dates from analyzed sites.

\begin{tabular}{|c|c|c|c|c|c|c|c|}
\hline Sitio & $\begin{array}{l}\text { Sector/com- } \\
\text { ponente }\end{array}$ & $\begin{array}{l}\text { Cuadrí- } \\
\text { cula }\end{array}$ & Nivel & Código & Fecha & Tipo & Fuente \\
\hline $\begin{array}{l}\text { Hospital } \\
\text { G16/1 }\end{array}$ & $\begin{array}{c}5 \\
6 \\
7 \\
8 / 9\end{array}$ & $\begin{array}{c}\text { 5ampl. } \\
6 \\
7 \\
9\end{array}$ & $\begin{array}{c}20-30 \mathrm{~cm} \\
50-60 \mathrm{~cm} \\
40-50 \mathrm{~cm} \\
0-10 \mathrm{~cm}\end{array}$ & $\begin{array}{l}\text { UCTL } 1228 \\
\text { UCTL } 1110 \\
\text { UCTL } 1109 \\
\text { UCTL } 1108\end{array}$ & $\begin{array}{l}850 \pm 110 \text { d.C. } \\
560 \pm 105 \text { d.C. } \\
555 \pm 150 \text { d.C. } \\
670 \pm 130 \text { d.C. }\end{array}$ & $\begin{array}{l}\text { TL } \\
\text { TL } \\
\text { TL } \\
\text { TL }\end{array}$ & $\begin{array}{c}* \\
\text { Vásquez et al. } 1999\end{array}$ \\
\hline $\begin{array}{l}\text { Lonquén } \\
\text { E80/4 }\end{array}$ & $\begin{array}{c}\text { I } \\
\text { II } \\
\text { III/IV } \\
\text { III/IV }\end{array}$ & $\begin{array}{c}1 \\
1 \mathrm{SW} \\
1 \mathrm{SW} \\
1\end{array}$ & $\begin{array}{l}3 \mathrm{c} \\
2 \mathrm{e} \\
1 \mathrm{e} \\
1 \mathrm{~b}\end{array}$ & $\begin{array}{l}\text { UCTL } 1230 \\
\text { UCTL } 1232 \\
\text { UCTL } 1231 \\
\text { UCTL } 1229\end{array}$ & $\begin{array}{l}85 \pm 200 \text { a.C. } \\
105 \pm 200 \text { a.C. } \\
970 \pm 100 \text { d.C. } \\
995 \pm 100 \text { d.C. }\end{array}$ & $\begin{array}{l}\text { TL } \\
\text { TL } \\
\text { TL } \\
\text { TL }\end{array}$ & $\begin{array}{l}* \\
* \\
* \\
*\end{array}$ \\
\hline $\begin{array}{l}\text { La Palma } \\
\text { E101/1 }\end{array}$ & & $\begin{array}{l}2 \\
4\end{array}$ & $\begin{array}{l}1 \mathrm{c} \\
2 \mathrm{a}\end{array}$ & $\begin{array}{l}\text { UCTL } 1269 \\
\text { UCTL } 1270\end{array}$ & $\begin{array}{l}750 \pm 100 \text { d.C. } \\
850 \pm 90 \text { d.C. }\end{array}$ & $\begin{array}{l}\text { TL } \\
\text { TL }\end{array}$ & * \\
\hline Chacayes & & & & GaK-6606 & $430 \pm 90$ d.C. & $\mathrm{C} 14$ & Stehberg 1978 \\
\hline $\begin{array}{l}\text { Radio Estación } \\
\text { Naval }\end{array}$ & & $\begin{array}{l}7 \\
7 \\
7\end{array}$ & $\begin{array}{l}215-225 \mathrm{~cm} \\
215-225 \mathrm{~cm} \\
185-195 \mathrm{~cm}\end{array}$ & $\begin{array}{c}\text { GaK-6405 } \\
\text { UCTL } 1098 \\
\text { UCTL } 1097 \\
\text { UCTL } 1096\end{array}$ & $\begin{array}{l}180 \pm 90 \text { a.C. } \\
110 \pm 200 \text { d.C. } \\
115 \pm 100 \text { d.C. } \\
175 \pm 160 \text { d.C. }\end{array}$ & $\begin{array}{l}\mathrm{C} 14 \\
\mathrm{TL} \\
\mathrm{TL} \\
\mathrm{TL}\end{array}$ & $\begin{array}{l}\text { Stehberg } 1976 \\
\text { Vásquez et al. } 1999\end{array}$ \\
\hline El Mercurio & II & $\begin{array}{l}\text { 2a } \\
2 \mathrm{c} \\
\text { Ent. } 5 \\
\text { C3 } \\
\text { C3 } \\
\text { I3 } \\
4 \mathrm{c} \\
\text { F5 } \\
\text { Ent. } 33 \\
\text { Ent. } 3 \\
\text { Ent. } 20 \\
\text { Ent. } 13\end{array}$ & $\begin{array}{c}150-170 \mathrm{~cm} \\
40-50 \mathrm{~cm} \\
\\
60-80 \mathrm{~cm} \\
40-60 \mathrm{~cm} \\
40-50 \mathrm{~cm} \\
40-50 \mathrm{~cm} \\
40-50 \mathrm{~cm}\end{array}$ & $\begin{array}{l}\text { UCTL } 189 \\
\text { UCTL } 985 \\
\text { UCTL } 311 \\
\text { UCTL } 188 \\
\text { UCTL } 187 \\
\text { UCTL } 986 \\
\text { UCTL } 987 \\
\text { UCTL } 988 \\
\text { UCTL } 270 \\
\text { UCTL } 269 \\
\text { UCTL } 272 \\
\text { UCTL } 271\end{array}$ & $\begin{array}{l}150 \pm 150 \text { d.C. } \\
370 \pm 100 \text { d.C. } \\
120 \pm 180 \text { d.C. } \\
300 \pm 140 \text { d.C. } \\
460 \pm 150 \text { d.C. } \\
470 \pm 100 \text { d.C. } \\
635 \pm 130 \text { d.C. } \\
805 \pm 120 \text { d.C. } \\
640 \pm 150 \text { d.C. } \\
680 \pm 130 \text { d.C. } \\
935 \pm 100 \text { d.C. } \\
1080 \pm 90 \text { d.C. }\end{array}$ & $\begin{array}{l}\text { TL } \\
\text { TL } \\
\text { TL } \\
\text { TL } \\
\text { TL } \\
\text { TL } \\
\text { TL } \\
\text { TL } \\
\text { TL } \\
\text { TL } \\
\text { TL } \\
\text { TL }\end{array}$ & $\begin{array}{l}\text { Falabella } 2000 \\
\text { Vásquez et al. } 1999 \\
\text { Falabella } 2000 \\
\text { Vásquez et al. } 1999 \\
\text { Falabella } 2000\end{array}$ \\
\hline $\begin{array}{l}\text { Parque La } \\
\text { Quintrala }\end{array}$ & III & $\begin{array}{l}6 \\
6\end{array}$ & $\begin{array}{c}5 \\
6 \\
7 \\
13 \\
7 \\
4\end{array}$ & $\begin{array}{l}\text { UCTL } 1101 \\
\text { UCTL } 1100\end{array}$ & $\begin{array}{c}280 \text { d.C. } \\
200 \text { d.C. } \\
20 \text { a.C. } \\
220 \text { d.C. } \\
180 \pm 180 \text { d.C. } \\
275 \pm 100 \text { d.C. }\end{array}$ & $\begin{array}{l}\text { TL } \\
\text { TL } \\
\text { TL } \\
\text { TL } \\
\text { TL } \\
\text { TL }\end{array}$ & $\begin{array}{l}\text { Thomas y Tudela } \\
1985 \\
\text { Vásquez et al. } 1999\end{array}$ \\
\hline $\begin{array}{l}\text { Pancho Pistolas } \\
\text { RML } 001\end{array}$ & & $\begin{array}{l}1 \mathrm{~A} \\
1 \mathrm{C}\end{array}$ & $\begin{array}{l}20-30 \mathrm{~cm} \\
30-40 \mathrm{~cm}\end{array}$ & $\begin{array}{l}\text { UCTL } 1005 \\
\text { UCTL } 1006\end{array}$ & $\begin{array}{l}435 \pm 100 \text { d.C. } \\
620 \pm 100 \text { d.C. }\end{array}$ & $\begin{array}{l}\mathrm{TL} \\
\mathrm{TL}\end{array}$ & \\
\hline $\begin{array}{l}\text { El Almendral } \\
\text { RML } 002\end{array}$ & & $\begin{array}{l}8 / 9 \mathrm{~A} \\
\mathrm{Z} 19\end{array}$ & $\begin{array}{c}0-50 \mathrm{~cm} \\
50-100 \mathrm{~cm}\end{array}$ & $\begin{array}{l}\text { UCTL } 1003 \\
\text { UCTL } 1004\end{array}$ & $\begin{array}{l}570 \pm 100 \text { d.C. } \\
270 \pm 150 \text { d.C. }\end{array}$ & $\begin{array}{l}\text { TL } \\
\text { TL }\end{array}$ & \\
\hline Los Panales & & $\begin{array}{l}1 \\
4\end{array}$ & $\begin{array}{l}5 \mathrm{a} \\
5 \mathrm{a}\end{array}$ & $\begin{array}{l}\text { UCTL } 694 \\
\text { UCTL } 693\end{array}$ & $\begin{array}{l}645 \pm 100 \text { d.C. } \\
765 \pm 100 \text { d.C. }\end{array}$ & $\begin{array}{l}\mathrm{TL} \\
\mathrm{TL}\end{array}$ & $\begin{array}{l}\text { Cornejo et al. } \\
1997\end{array}$ \\
\hline El Manzano 2 & & $\begin{array}{l}4 \\
5 \\
4 \\
4 \\
4\end{array}$ & $\begin{array}{l}1 \mathrm{~b} \\
2 \mathrm{a} \\
2 \mathrm{a} \\
1 \mathrm{a} \\
4 \mathrm{~b}\end{array}$ & $\begin{array}{l}\text { UCTL } 1217 \\
\text { UCTL } 1126 \\
\text { UCTL } 1216 \\
\text { UCTL } 1123 \\
\text { UCTL } 1125\end{array}$ & $\begin{array}{l}470 \pm 150 \text { d.C. } \\
640 \pm 140 \text { d.C. } \\
670 \pm 140 \text { d.C. } \\
795 \pm 120 \text { d.C. } \\
910 \pm 110 \text { d.C. }\end{array}$ & $\begin{array}{l}\text { TL } \\
\text { TL } \\
\text { TL } \\
\text { TL } \\
\text { TL }\end{array}$ & $\begin{array}{l}\text { Cornejo y Galarce } \\
2000\end{array}$ \\
\hline
\end{tabular}

* Estos fechados no han sido previamente publicados y fueron obtenidos en el marco del proyecto Fondecyt 1970910. These dates have not been previously published, and they are the product of Fondecyt grant 1970910. 
El sitio Lonquén E80/4 se localiza ca. 700 m al poniente del cerro homónimo (UTM E 328400 N 6269500). Cubre una superficie de aproximadamente $150.000 \mathrm{~m}^{2}$ y presenta un depósito profundo de 1,5 m. A partir del análisis de los materiales, principalmente de la cerámica, identificamos en un principio cuatro ocupaciones estratigráficamente superpuestas, presentando las dos inferiores y las dos superiores mayores similitudes entre sí. Los fechados realizados en una primera instancia mostraron que las dos primeras y las dos últimas eran prácticamente contemporáneas respectivamente (Tabla 1). Ciertas dudas nos llevaron a realizar otro fechado para el tercer momento ocupacional, que esta vez dio un resultado de $260 \pm 175$ d.C. La reevaluación de la secuencia de cuatro momentos propuesta inicialmente a la luz de los fechados nos llevó a proponer la siguiente situación. A pesar de la contemporaneidad e incluso la inversión de los fechados de los dos primeros momentos ocupacionales, seguimos pensando que efectivamente se trata de dos ocupaciones distintas, ya que las diferencias entre los materiales de ambas son sustantivas y no pueden ser explicadas satisfactoriamente por otros motivos; estas ocupaciones podrían ser muy próximas en el tiempo, lapso que puede quedar incluido en los sigmas de los fechados, dada la resolución que los métodos de datación con que contamos. Las diferencias identificadas entre las ocupaciones superiores, sin embargo, podrían deberse a condiciones de conservación del material, por lo que lo que inicialmente fue planteado como dos ocupaciones, pueden ser considerado como una (Lonquén III/IV). El fechado temprano del tercer momento ocupacional propuesto inicialmente lo interpretamos como producto de mezcla de materiales de las ocupaciones tempranas de abajo y las más tardías de arriba. Esta mezcla, sin embargo, no sería de gran magnitud, ya que priman todas las características que lo asemejan a lo que inicialmente llamamos cuarta ocupación, hecho que es consistente tanto en relación al material cerámico como al lítico.

El sitio La Palma E101/1 está localizado entre Talagante y El Monte y entre los ríos Mapocho y Maipo (UTM E 318250 N 6271300). Cubre una superficie de al menos $70.000 \mathrm{~m}^{2}$ y la profundidad del depósito varía entre 60 y $100 \mathrm{~cm}$. Si bien los materiales presentan ciertas diferencias en los distintos estratos, pensamos que corresponden a una sola ocupación (Tabla 1).
Las colecciones de materiales revisadas corresponden a los sitios Chacayes (CHY) y Radio Estación Naval (REN), depositadas en el MNHN; y El Mercurio, Parque La Quintrala (PLQ), RML 001 Pancho Pistolas, RML 002 El Almendral y RML 051 estero Lampa, depositadas en la Facultad de Ciencias Sociales de la Universidad de Chile. Como mencionamos con anterioridad, algunas de estas colecciones se encontraban disminuidas, hecho que afectó especialmente al material lítico, por lo que sólo se cuenta con información parcial de algunas de ellas (Tabla 2).

El sitio Chacayes (CHY) se ubica en la alta cordillera (1570 msm), en el margen sur del curso superior del río Yeso (Cajón del Maipo) en la terraza alta del valle, que en este sector es bastante amplia. Se trata de un sitio habitacional y funerario, donde se recuperaron al menos 14 individuos y cuenta con un fechado sobre hueso humano (Stehberg 1978) (Tabla 1).

El sitio Radio Estación Naval (REN) se ubica en la comuna de Quinta Normal (Santiago), dentro de un recinto de la Armada inmediatamente al poniente del parque del mismo nombre. Se obtuvo un fechado C14 sobre hueso humano (Stehberg 1976) (Tabla 1). El año 1998 realizamos una cuadrícula de 1,5 x 1,5 m con el objeto de instalar dosímetros para refechar el sitio. El material extraído fue incorporado a la colección, analizado y fechado (Tabla 1).

Tabla 2. Colecciones analizadas y su condición. Analyzed collections and their conditions.

\begin{tabular}{l|c|c|c}
\hline \multirow{2}{*}{\multicolumn{1}{c|}{ Sitios }} & \multicolumn{3}{c}{ Materiales } \\
\cline { 2 - 4 } & \multicolumn{2}{|c}{ Cerámica } & Lítico \\
\cline { 2 - 4 } & $\begin{array}{c}\mid c \\
\text { piezas }\end{array}$ & fragmentos & \\
\hline El Mercurio & $\mathrm{x}$ & $\mathrm{x}$ & $\mathrm{x}$ \\
Parque La Quintrala & $\mathrm{x}$ & $\mathrm{x}$ & - \\
Pancho Pistolas & & $\mathrm{x}$ & $\mathrm{x}$ \\
El Almendral & & $\mathrm{x}$ & $\mathrm{x}$ \\
Estero Lampa & & $\mathrm{x}$ & $\mathrm{x}$ \\
Chacayes & $\mathrm{x}$ & $\mathrm{x}$ & $*$ \\
Radio Estación Naval & & $\mathrm{x}$ & $*$ \\
\hline
\end{tabular}

x colección completa

* colección incompleta

- material no disponible para análisis. 
El sitio El Mercurio (EM) se sitúa en la terraza fluvial de la ribera norte del río Mapocho, a los pies del cerro Manquehue y fue descubierto durante faenas de movimiento de tierra. El sector habitacional del sitio tiene un depósito de hasta 1 $\mathrm{m}$ de profundidad en casi todos los sectores y se pudieron identificar dos componentes (Falabella 2000). Asociado a éste se encuentra un área de cementerio donde se identificaron 36 enterratorios, con diversas ofrendas y ajuar. Ambos componentes cuentan con fechados (Tabla 1).

El sitio Parque La Quintrala (PLQ) se ubica sobre un cono de deyección de la Quebrada San Ramón, en la comuna de La Reina de la ciudad de Santiago. El sitio cuenta con un depósito de basuras habitacionales de hasta $3 \mathrm{~m}$ de profundidad, $\mathrm{y}$ de un área de funebria donde se recuperaron 10 enterratorios (Thomas et al. 1980). Los análisis llevados a cabo por dichos investigadores, confirmados por los nuestros, identificaron dos ocupaciones del sitio. Ambas se encuentran fechadas ${ }^{7}$ (Tabla 1).

El sitio Pancho Pistolas RML 001 está ubicado en el sector norte de la Hacienda Chicauma, entre los esteros Polpaico y Chacabuco, en las cercanías de su confluencia, en la comuna de Lampa (Lat. 3311'15'; Long. 7053'7'). El sitio tiene una extensión aproximada en superficie de $200 \mathrm{x}$ $300 \mathrm{~m}$ (Thomas et al. 1990). Se obtuvieron dos fechados TL (Tabla 1).

El sitio El Almendral RML 002 está ubicado en el sector sur de la Hacienda Chicauma, en la ribera oeste del estero Chacabuco, en las cercanías de su confluencia con el estero Polpaico, en la comuna de Lampa (Lat. 3311'30"'; Long. 7053'31'). Este sitio fue descubierto por la construcción de una casa en el sector, la cual dejó al descubierto algunos enterratorios, realizándose un salvamento (Thomas et al. 1990). Se realizaron dos fechados TL (Tabla 1).

El sitio estero Lampa RML 051 es un sitio habitacional ubicado en la ladera oeste del cerro Chepo, en la confluencia de los esteros Chacabuco y Polpaico, en la comuna de Lampa (Lat. 3311'44"; Long. 7053'46") (Thomas et al. 1990). La extensión del sitio no fue determinada. No cuenta con fechados absolutos, pero su asignación al PAT, dada la características de sus materiales, es indudable.

Por último también se consideraron los materiales de dos sitios excavados en el marco de otras investigaciones en marcha que contaban con ocupaciones tempranas: Los Panales y El Manzano 2, cuyos materiales fueron analizados por el mismo equipo de trabajo.

Los Panales (LPN) está ubicado a 1350 msm en una terraza aluvial en el lado este del estero Cabeza de León, a poca distancia de su confluencia con río Colorado, en el interior del cajón del Maipo. El sitio, catalogado como un campamento habitacional al aire libre orientado a actividades mineras, tiene un depósito de ca. $40 \mathrm{~cm}$ de espesor y cuenta con dos fechados TL (Cornejo et al. 1997) (Tabla 1).

El Manzano 2 (Ma2) es un sitio bicomponente ubicado a $920 \mathrm{msm}$ en la terraza norte de la confluencia del estero El Manzano con el río Maipo. Si bien este sitio fue registrado y sondeado bajo el marco de investigaciones anteriores (Cornejo 2000), fue a partir de las excavaciones realizadas por el proyecto Fondecyt 1980713 que se logró identificar una ocupación perteneciente al período alfarero temprano bajo la ocupación Aconcagua. Si bien ambos depósitos se encuentran muy mezclados, por lo que es prácticamente imposible realizar análisis cuantitativos de los materiales recuperados, tanto las características de sus materiales como sus fechados TL nos llevaron a considerarlo dentro de este estudio (Tabla 1).

\section{Las Asociaciones Contextuales del Período Alfarero Temprano en Chile Central}

De acuerdo a lo señalado en los acápites anteriores, e integrando la información analizada con variables espaciales y cronológicas, proponemos el siguiente panorama para el PAT en Chile central.

\section{Las comunidades alfareras iniciales}

Desde los inicios de la alfarería en esta zona, hasta alrededor de 200 d.C., los contextos arqueológicos presentan ciertas características que permiten diferenciar este primer momento dentro del $\mathrm{PAT}^{8}$. Este momento sería producto de 'comunidades alfareras iniciales', nombre utilizado por Falabella y Stehberg (1989) para estos grupos y que nosotros retomamos (Sanhueza y Falabella 1999-2000). La propuesta y discusión de las evidencias ha sido desarrollada en otro trabajo (San- 
hueza y Falabella 1999-2000), por lo que aquí sólo presentaremos una breve síntesis.

Evidencias de estas ocupaciones se encuentran tanto en el valle central como en la costa de la región, en las dos primeras ocupaciones del sitio Lonquén (E80/4) y REN entre los sitios analizados por nosotros, pero también en una serie de otros sitio publicados con anterioridad como por ejemplo Curaumilla 1 y 2, LEP-C primera ocupación, Arévalo 2 primera y segunda ocupación (Sanhueza y Falabella 1999-2000).

La cerámica de estas comunidades se caracteriza por ser mayoritariamente de paredes delgadas y tener formas simples de perfiles inflectados, en general sin asas o con asas mamelonares si es que las presentan. La variedad de decoraciones es restringida, siendo la más importante la pintura roja, aunque también hay hierro oligisto y en algunos casos pintura roja sobre un engobe crema.

El material lítico de los contextos mencionados previamente ha sido definido como un contexto artefactual de caza, caracterizado por la presencia de puntas de proyectil ${ }^{9}$, alta variabilidad de materias primas de grano fino e instrumentos de faenamiento y procesamiento de presas. Por otra parte, destaca un contexto de molienda con manos discoidales con un marcado proceso de modificación y caras activas plano-convexas asociadas a molinos planos ${ }^{10}$.

Las características del material lítico, específicamente de las puntas y manos de moler, permiten plantear similitudes morfológicas con sus símiles del período Arcaico, especialmente con el sitio Cuchipuy (Kaltwasser et al. 1980), aun cuando estos contextos están distanciados por cerca de 2000 años. Por otra parte, la presencia de puntas de proyectil triangulares de base escotada señalan relaciones morfológicas con la tradición arcaica de puntas triangulares descritas por Vera (1998), especialmente para el período Arcaico IV, definido para la precordillera de Chile central.

Así, la subsistencia de estos grupos estaría basada en la caza y también fuertemente en la recolección. La presencia de cultígenos es probable hacia los 100 a.C. ${ }^{11}$ (Belmar y Quiroz 1999, 2000).

\section{Los desarrollos culturales posteriores del período alfarero temprano}

En tiempos posteriores o incluso parcialmente contemporáneos con el final de las comunida- des alfareras iniciales, la cerámica muestra características que evidencian una diversificación del panorama cultural de la región, asociado a un proceso de normalización de la tecnología, formas y decoraciones cerámicas.

Nuestros estudios nos han permitido reconocer al menos cuatro situaciones diferentes y contemporáneas dentro de esta etapa del PAT. Estas unidades fueron identificadas y definidas de acuerdo al enfoque analítico expuesto con anterioridad, por lo que no son internamente homogéneas.

\section{Llolleo}

Los sitios estudiados que hemos agrupado en la unidad Llolleo son El Mercurio, Los Panales y Hospital-6, los que cubren un amplio rango temporal (300-800 d.C.).

En relación a la tecnología de producción cerámica, la principal característica es la predominancia de la pasta U (Tabla 3), que se utiliza para confeccionar prácticamente todas las categorías de vasijas de los conjuntos cerámicos, ya que se encuentra presente tanto en las vasijas alisadas como pulidas y decoradas.

Si bien las vasijas pueden tener distintas formas, las más frecuentes, tanto pulidas como alisadas, tienen perfiles compuestos, con una o dos asas en arco de correa, y bases delimitadas. En ocasiones los bordes de estas vasijas pueden presentar refuerzo. Otras formas, mucho menos frecuentes, son las vasijas asimétricas (tipo jarro pato) y las abiertas (Tabla 4).

Las decoraciones características abarcan una variedad de técnicas (pintado, inciso, modelado) y combinaciones de ellas (pintado e inciso, modelado e inciso), que adoptan motivos y configuraciones específicos (Tabla 4). Es así como la pintura roja puede cubrir toda la pieza o formar motivos compuestos por bandas. Cuando se combina con hierro oligisto, adopta configuraciones determinadas (líneas rojas escaleradas u ondulantes verticales sobre campos de hierro oligisto, o bien franjas anchas alternadas de hierro oligisto y rojo). Los incisos lineales son frecuentes, y pueden adoptar configuraciones como incisiones anulares en la base del cuello e incisiones reticuladas oblicuas en el cuello, pero también otras que no conocemos. Cuando las incisiones se combinan con la pintura roja, éstas delimitan y separan campos geométricos pintados de otros sin pintar. Los modelados e 


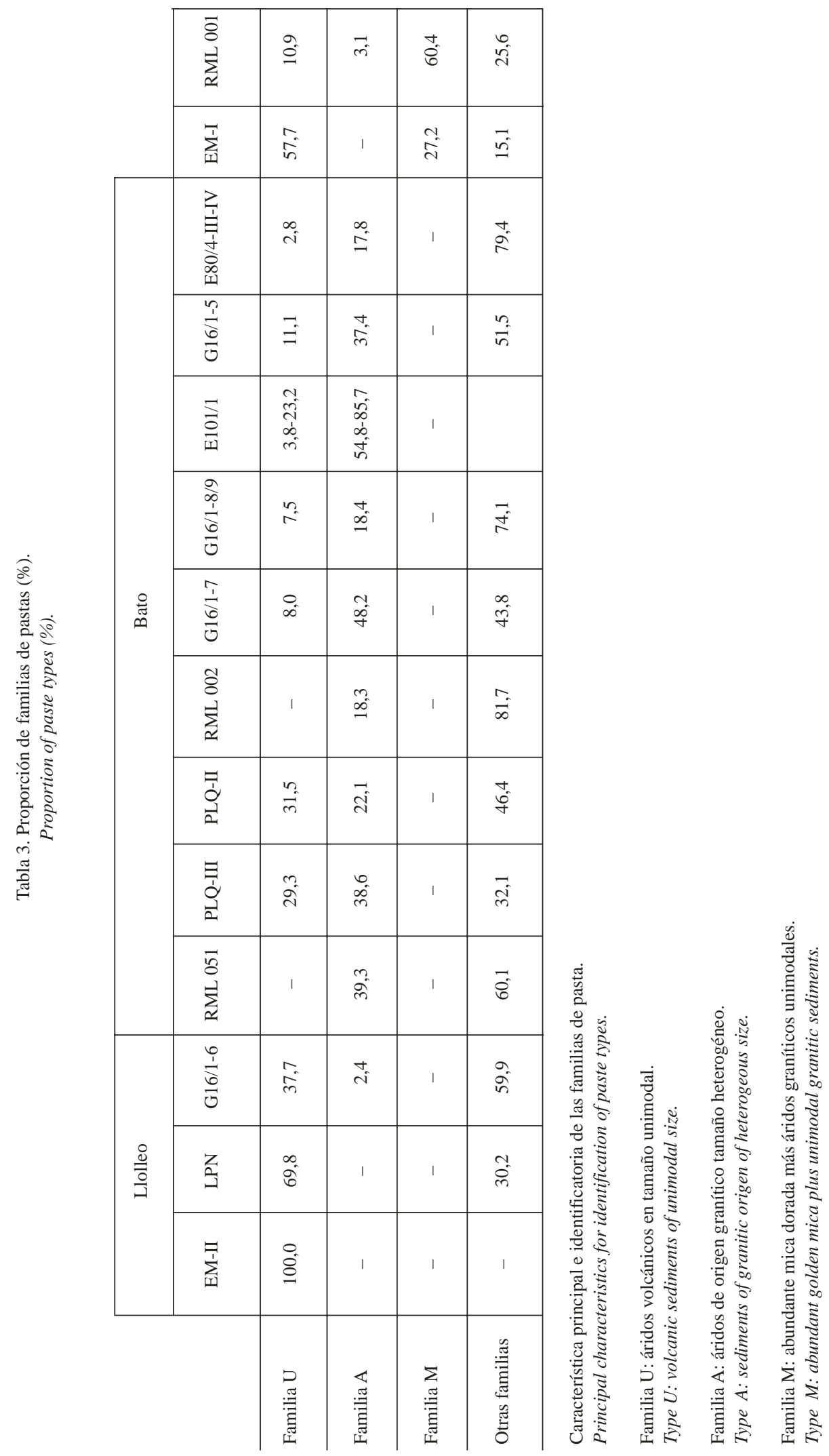



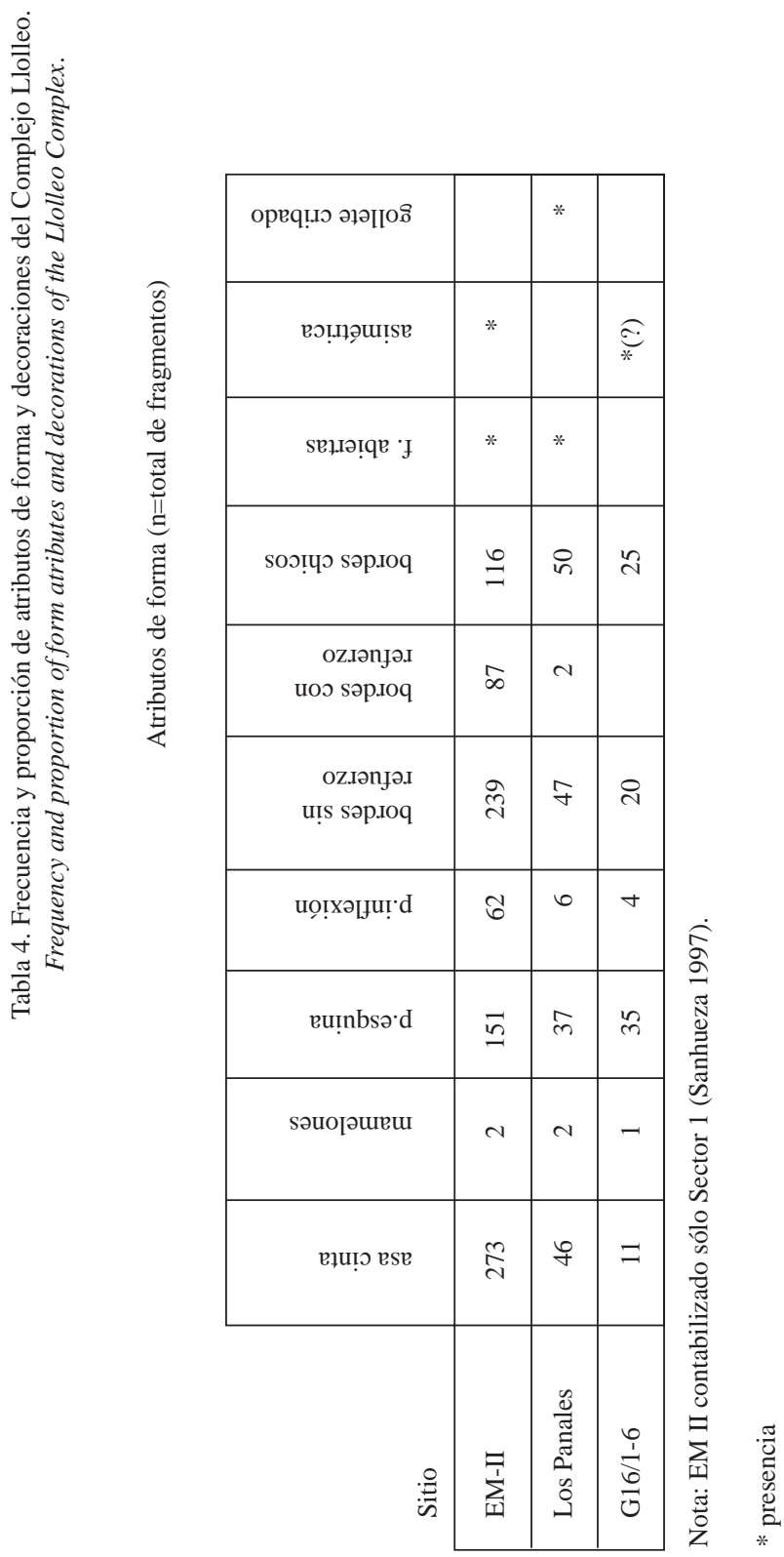

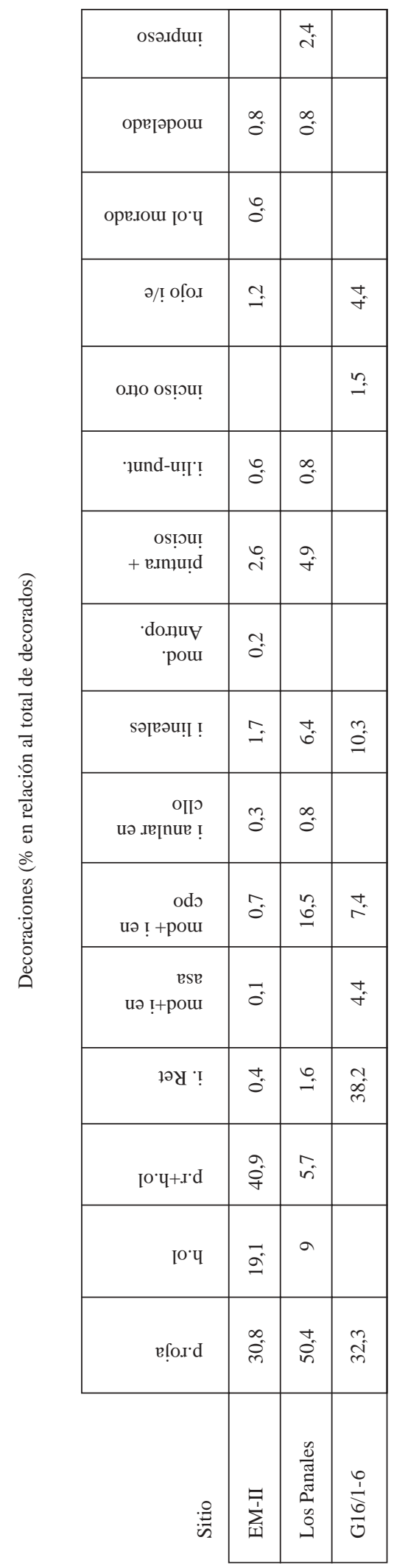


incisos pueden constituir unidades discretas ("mamelones incisos") o bien bandas de largo indeterminado $^{12}$. Dentro de la primera categoría se incluyen los mamelones incisos en las asas, que son la contraparte de las decoraciones incisas reticuladas, ya que en las vasijas enteras éstos dos elementos se encuentran generalmente asociados ${ }^{13}$.

Como ya lo anticipáramos, los contextos agrupados en esta unidad no son homogéneos, sino que así como presentan similitudes que permitieron agruparlos, también presentan ciertas diferencias. El aspecto que presenta mayor variabilidad es la decoración (Tabla 4).

La ocupación de Hospital-6 es la que presenta mayores diferencias. Al tratarse del sitio donde menos excavaciones se realizaron y, por tanto, con menor cantidad de materiales analizados, éstas diferencias podrían deberse al pequeño tamaño de la muestra, lo que afecta especialmente a los elementos escasos como las decoraciones y ciertas formas. Esto sin considerar otros factores que también podrían estar influyendo, como el aspecto funcional.

El contexto lítico, definido a partir de El Mercurio y Los Panales, se configura como un contexto no orientado a la caza debido a la muy baja incidencia de puntas de proyectil (sólo dos preformas en El Mercurio y una en Los Panales), junto con la escasísima presencia de registro arqueofaunístico.

Uno de los rasgos relevantes del sitio El Mercurio es la importante frecuencia de un complejo artefactual de molienda dirigido a la producción de harina, con manos de moler a partir de nódulos naturales predominantemente sin modificación, asociados a molinos con canal de molienda muy definido con sección en "U" (Vásquez 2000). Debemos destacar que los molinos tienen una participación activa en los ritos mortuorios de este grupo, conducta que se puede correlacionar con la presencia de molinos en acumulaciones de piedra en el sitio La Granja (cuenca de Rancagua) asignado a esta unidad cultural (Tagle 1996). La orientación hacia la molienda de esta población debe correlacionarse con los resultados obtenidos por Falabella et al. (1995-1996) de la aplicación de rayos-X sobre huesos humanos en individuos del sitio EM, en la cual la relación entre elementos traza ( $\mathrm{Zn}, \mathrm{Ca}$ y $\mathrm{Sr}$ ) fue interpretada como el resultado del consumo de cultígenos por parte de esta población. Es importante destacar que estos datos son coherentes con la evidencia de caries profundas en los individuos (Solé 1991).
El sitio El Mercurio presenta también un área de funebria asociada al área habitacional. Esta se caracteriza por presentar individuos en posición flectada y frecuentemente están asociados a acumulaciones de grandes bolones de río formando hileras y que aparentemente han sido depositados como ofrenda. La mayoría de ellos tienen además ofrendas de vasijas cerámicas completas, algunos morteros (formando parte de las estructuras de bolones) y piedras horadadas. Como ajuar presentan collares de cuentas discoidales. La mayoría de los párvulos y niños están depositados en urnas y tienen las mismas ofrendas que los adultos (Falabella 2000).

\section{Bato}

Las ocupaciones asignadas a esta unidad son Parque La Quintrala I, Parque La Quintrala II, El Almendral, Estero Lampa, Hospital-7, Hospital-8/9, Lonquén III/IV, Hospital-5, La Palma y El Manzano 2, que abarcan un rango temporal que va desde finales del segundo siglo de nuestra era hasta prácticamente el final del primer milenio.

Si bien en esta unidad hemos podido integrar un mayor número de ocupaciones, también es cierto que presenta una mayor variabilidad interna. Dada su extensión temporal, parte de las diferencias puede ser explicada por factores cronológicos, pero otra parte se debe a factores sociales.

El elemento que une a todas las ocupaciones, tanto contemporáneas como separadas en el tiempo, es el factor tecnológico en la cerámica, ya que en todas ellas la familia de pastas A es la más importante (a excepción en Hospital-8/9). No existe una relación específica entre estas familias de pastas con ciertas categorías de vasijas, sino que se encuentran tanto en vasijas alisadas y pulidas como en vasijas decoradas (Tabla 3 ).

Respecto a las formas, las más frecuentes son las ollas y jarros que tienen en frecuencias comparables los perfiles compuestos e inflectados ${ }^{14}$. Estas por lo general no presentan asas, pero cuando lo hacen pueden ser tanto del tipo en arco de correa (cinta) como mamelonar. Las vasijas pulidas generalmente no tienen asas (Tabla 5).

Es frecuente encontrar en estos contextos fragmentos que indican la presencia de categorías morfológicas distintas a las clásicas ollas y jarros, pero al no contar con vasijas completas como referente para ellas, su reconstrucción es difícil, del 

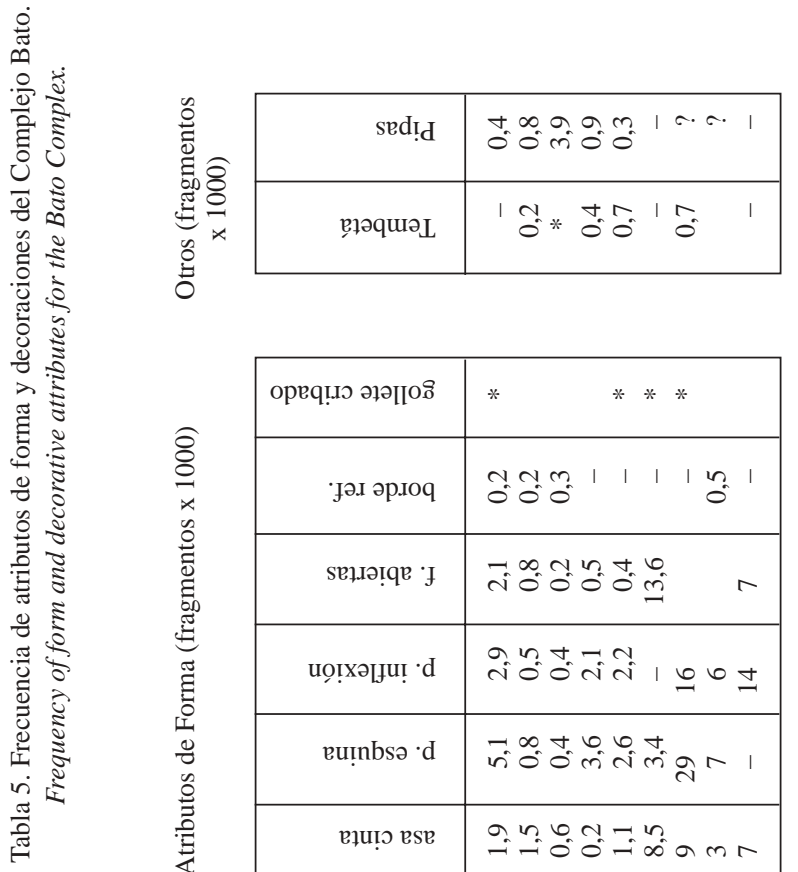

\begin{tabular}{|c|c|}
\hline 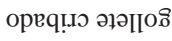 & $* * *$ \\
\hline 'Јәл әр.оо & 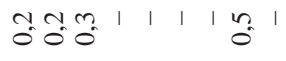 \\
\hline 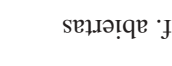 & 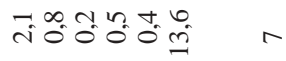 \\
\hline 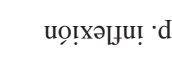 & 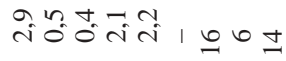 \\
\hline вu!̣nbsə $\cdot d$ & 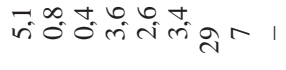 \\
\hline вұụ़ ese & $\Rightarrow \because 0 \tilde{0}=\infty$ \\
\hline sәиорәивш & 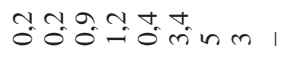 \\
\hline
\end{tabular}

\begin{tabular}{|c|c|}
\hline osə.du! ’ $\mathrm{d}_{\text {II }}$ & $\stackrel{0}{0}$ \\
\hline ọ̣o. วqовินว & ? \\
\hline орегәрош & 중: \\
\hline $\begin{array}{r}\text { oपวur } \\
\text { [вәu!̣ oṣ̣u! }\end{array}$ & 웅 \\
\hline 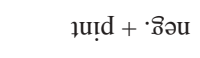 & है \\
\hline вщшә.э/s ofo. & $\stackrel{t}{0}_{0}^{t} \quad \stackrel{t}{0}$ \\
\hline 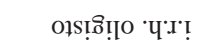 & 공 \\
\hline 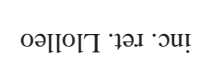 & $\because 0$ \\
\hline ·'su! + pou & 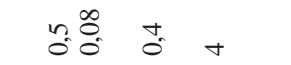 \\
\hline 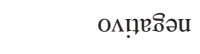 & कू कू \\
\hline 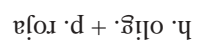 & $\stackrel{n}{n} \rightarrow=0$ \\
\hline 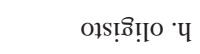 & nof Fin \\
\hline 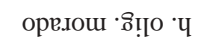 & 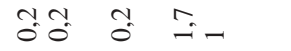 \\
\hline 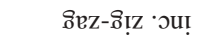 & - \\
\hline 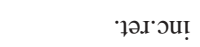 & $\bar{n} \sin ^{n}$ \\
\hline [вәш! 'כu! & 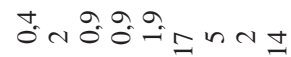 \\
\hline 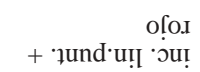 & $\begin{array}{l}\infty \\
\infty \\
\infty\end{array}$ \\
\hline 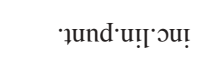 & 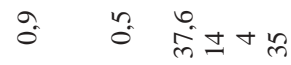 \\
\hline $\mathrm{g} / \mathrm{I} \mathrm{e}[\mathrm{fox} \cdot \mathrm{d}$ & ơñ \\
\hline ẹo. $\cdot d$ & 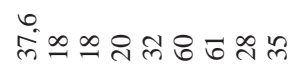 \\
\hline 昜 & 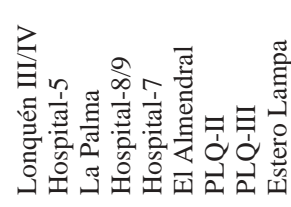 \\
\hline
\end{tabular}


mismo modo que es difícil evaluar su importancia relativa. Además, muchas veces parece tratarse de formas no muy frecuentes en los contextos, por lo que su presencia o ausencia debe evaluarse con cautela. La mayoría de éstos fragmentos indican la presencia de cuerpos tubulares, cuellos muy angostos y largos y, en algunos sitios, puntos de quiebre en el cuerpo. Una categoría morfológica que podría corresponder a estos fragmentos es similar a las "lagenarias" de Chacayes, pero que en el valle adoptan una forma más tubular (Fig. 19, Oyarzún 1979 [1910] y dos vasijas de Isla de Maipo en colección particular). Otra categoría morfológica que también puede dar cuenta de parte de ellos es la vasija asimétrica con dos golletes, cuya presencia efectiva hemos podido constatar en las ocupaciones de Parque la Quintrala II, El Almendral, Hospital-7 y Lonquén III, a partir de la presencia de fragmentos de disco cribado. En El Almendral, el fragmento tiene además un fragmento del asa que es del tipo en arco de correa, lo que marca una diferencia sustantiva con las vasijas del mismo tipo de Chacayes, cuyas asas son circulares huecas.

Las decoraciones (Figuras 2 y 3 ) son el aspecto más variable y el que permite establecer subconjuntos dentro de la unidad. En estricto sentido, la única decoración común a todas estas ocupaciones es la pintura roja, pero ésta también es común a todas las demás unidades del PAT (Tabla 5).

En relación al material lítico de los sitios que asignamos a esta unidad cultural, es posible definirlo como un contexto artefactual de caza, caracterizado por la presencia de puntas de proyectil ${ }^{15}$, alta frecuencia de materias primas de grano fino (cuarzo, cuarcitas, jaspe, obsidiana) e instrumentos de faenamiento y procesamiento de presas.

Sólo tenemos información de un enterratorio recuperado de la ocupación de Hospital-8/9 para caracterizar las prácticas funerarias de esta unidad, por lo que no podemos configurar un patrón de funebria propiamente tal ${ }^{16}$. En el sector inmediatamente aledaño al lugar donde se recuperó este enterratorio había evidencia de la existencia de otros enterratorios, lo que indica que probablemente hubo un área de funebria aledaña (o superpuesta) al área habitacional. El entierro se encontraba a escasa profundidad $(25 \mathrm{~cm})$ y estaba en posición decúbito ventral con las piernas hiperflectadas hacia atrás a la altura de las rodillas (Reyes 1998). No presentaba ofrenda ni ajuar.
El tembetá es un elemento relativamente frecuente dentro de esta unidad, aunque no todos los contextos lo presentan. El tipo más abundante es el discoidal con alas, elaborado tanto de cerámica como en piedras de baja dureza. Si bien la distribución de los tembetás en términos de su importancia y de sus característica no es homogénea, lo que nos plantea una diferenciación al interior de esta unidad, no hemos podido hasta ahora establecer un ordenamiento significativo a partir de ellos.

Pese a que aún se cuenta con pocas evidencias para caracterizar de manera adecuada las diferencias internas dentro de esta unidad (ya que las apreciaciones actuales podrían cambiar con un aumento de la muestra), pensamos que constituyen una base suficiente para proponer estas diferencias como hipótesis (Tabla 5).

Un primer momento en la secuencia de esta unidad, representado por las ocupaciones de Parque La Quintrala III y II, El Almendral y Estero Lampa $^{17}$, se desarrolla entre el 200 y el 600 d.C. y se caracteriza por presentar una variedad de decoraciones relativamente restringida, donde la pintura roja es muy frecuente. La decoración incisa, en general, tiene mayor importancia que en el momento posterior, tanto en términos de frecuencia como en términos de variedad (incisiones lineales, lineales y punteadas, reticuladas, en zigzag) y la decoración incisa lineal y punteada es mucho más frecuente (Figura 2).

El sitio El Almendral (única ocupación con material lítico analizado), nos indica un contexto cultural de orientación a la caza asociado a contextos de molienda descritos para las comunidades iniciales del PAT con fechas tan tardías como 270570 d.C. Lamentablemente, no se contó con el material lítico de las dos ocupaciones de Parque La Quintrala que habría podido definir de mejor manera esta situación.

A partir de ca. 600 d.C., en las ocupaciones de los sitios Hospital-5, Hospital-7, Hospital-8/9, Lonquén III/IV y La Palma, se observan ciertos cambios al interior de esta unidad. En la cerámica, lo principal es que las decoraciones se diversifican. La pintura roja pierde algo de su importancia en relación al momento anterior y el inciso lineal punteado baja notoriamente sus frecuencias. Aparecen nuevas decoraciones, como la combinación de pintura roja y hierro oligisto (a veces en combinación con incisiones) y modelados; nuevos motivos y configuraciones para los incisos (incisiones 


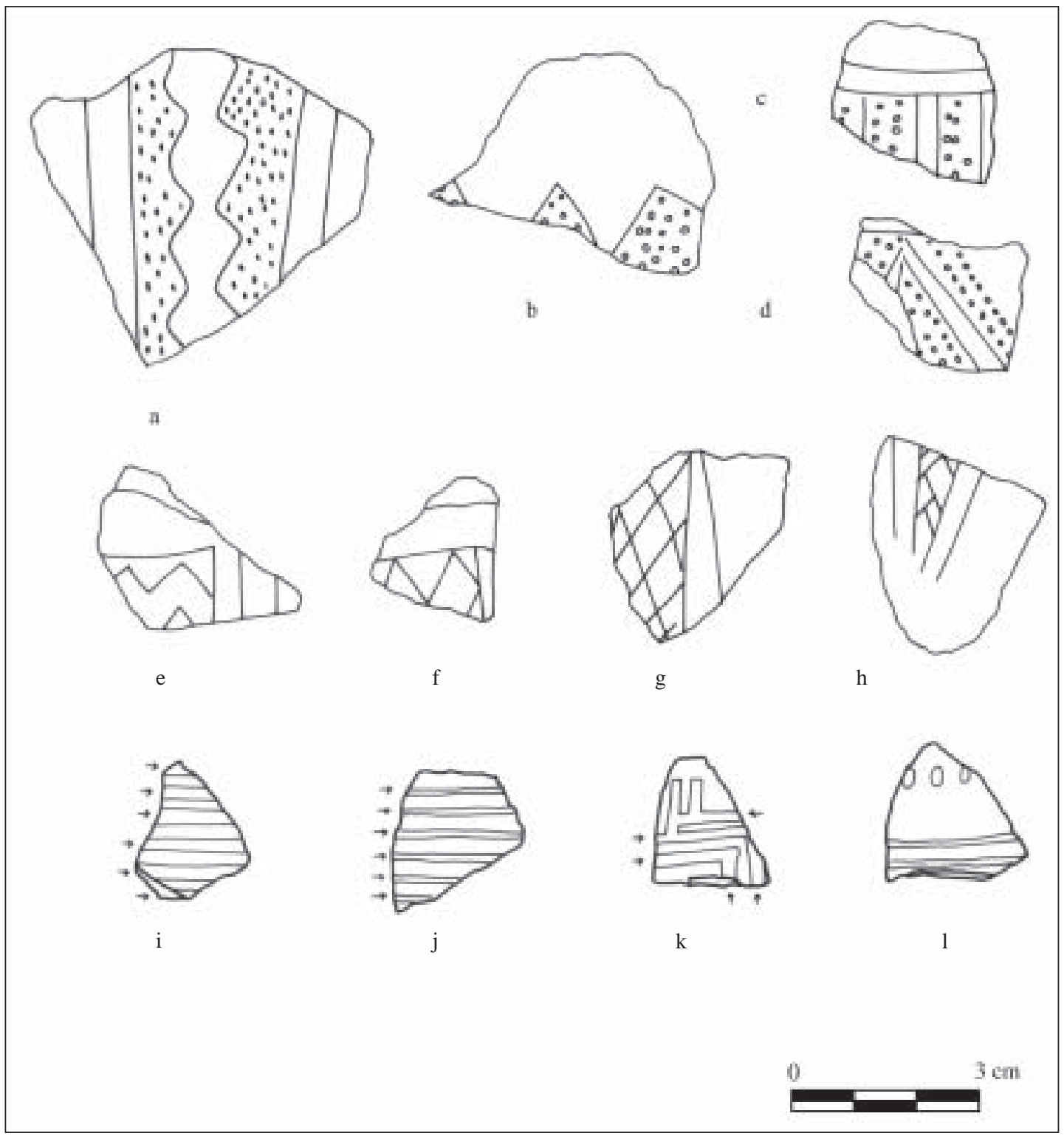

Figura 2. Decoraciones complejo Bato: (a), (b), (c), (d), inciso lineal punteado; (e), (f), incisiones en zigzag; (g), (h), incisiones reticuladas; (i), (j), (k), incisiones anchas; (1), incisiones anchas y círculos impresos.

Procedencia a-h: PLQ; i, j, 1: E101/1 y k: G16/1-8/9.

Decorations of the Bato complex: $(a),(b),(c),(d)$, dotted incised line; $(e),(f)$, zigzagged incisions; $(g),(h)$, reticulated incisions; $(i),(j),(k)$, wide incisions; $(l)$, wide incisions and printed circles.

Provenience a-h: PLQ; $i, j, l:$ E101/1 and $k:$ G16/1-8/9.

reticuladas en cuellos e incisiones anchas); y reaparecen antiguas decoraciones que tendrían sus orígenes con las comunidades alfareras iniciales (rojo sobre engobe crema) (Figuras 2 y 3). Respecto a las formas destaca la aparición, aunque en escasa cantidad, de los bordes reforzados.
Dentro de este momento más tardío, se diferencian del resto claramente dos ocupaciones: $\mathrm{La}$ Palma y Hospital-5. Estas dos son las únicas que no presentan decoración incisa lineal y punteada y son las que tienen en general la mayor variedad de decoraciones. La presencia de decoraciones incisas 


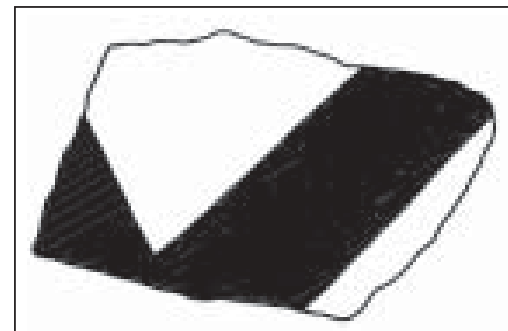

a

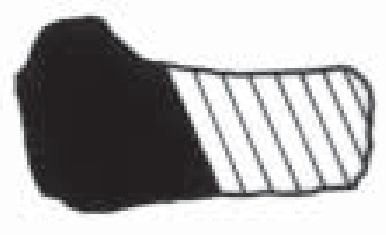

d

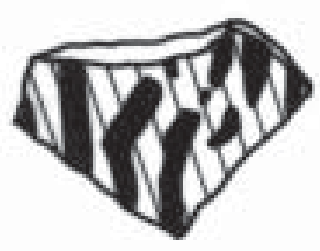

g
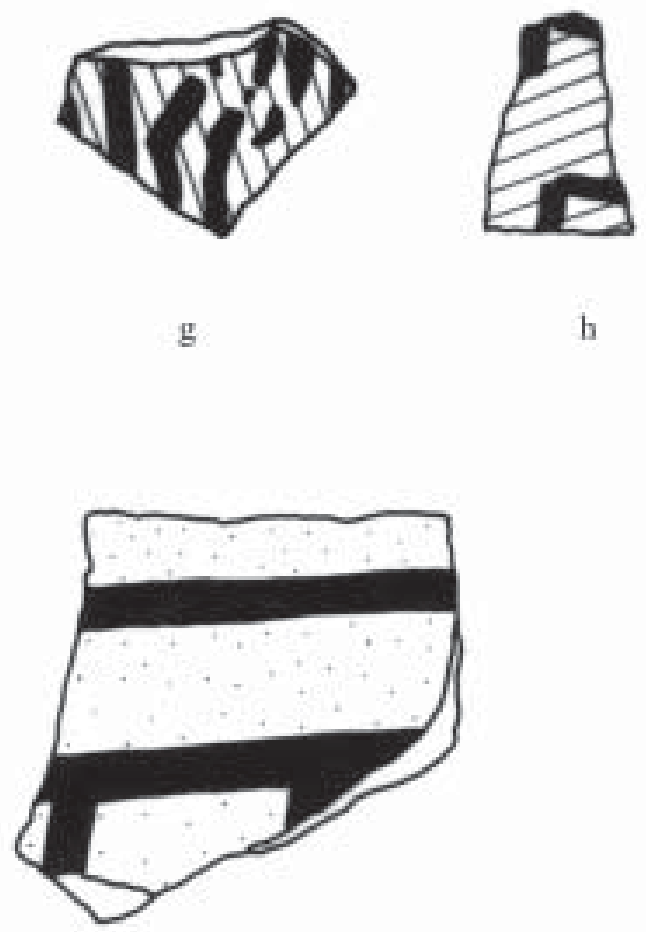

b

b

e
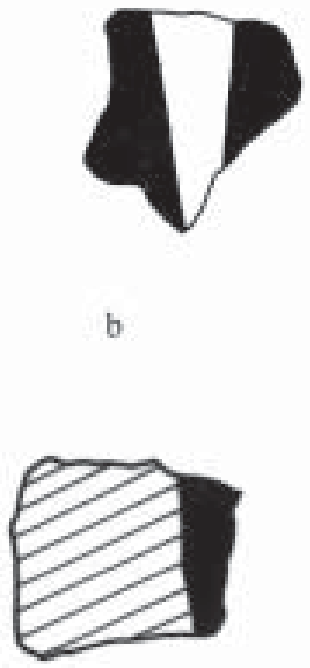

f
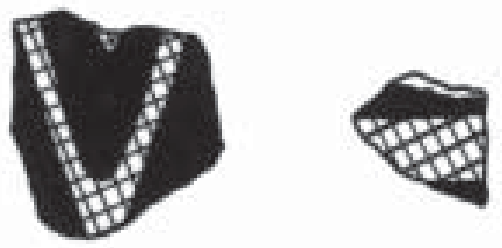

Superficie natural

Rojo

Hierro oligisto

Blanco

Ahumado

k

0

$3 \mathrm{~cm}$

Figura 3. Decoraciones Complejo Bato: (a), (b) franjas rojas; (c) pintura roja y hierro oligisto separados por incisión; (d), (e), (f), (g), (h) rojo y hierro oligisto; (i), (j) técnica negativa; (k) rojo sobre crema.

Procedencia: a, b: PLQ; c, d, h, i: E80/4; e, f, k: E101/1; g, j: G16/1-5.

Bato Complex Decorations: (a), (b) red stripes; (c) red paint and hematite separated by incisions; $(d),(e),(f),(g),(h)$ red and hematite; ( $i),(j)$ negative technique; $(k)$ red on beige.

Provenience: $a, b: P L Q ; c, d, h, i: E 80 / 4 ; e, f, k: E 101 / 1 ; g, j: G 16 / 1-5$. 
reticuladas en el cuello, que podrían considerarse del tipo Llolleo, junto con la mayor relevancia del oligisto, nos hizo considerar en un primer momento la posibilidad de que se tratara de un contexto 'mezclado', con restos de ocupaciones de otras unidades (v. gr. Llolleo), que nosotros no pudimos diferenciar por encontrarse los depósitos muy revueltos.

En el sitio Hospital-5, el resto del contexto es muy escaso como para poder aclarar este punto, pero en el caso del sitio La Palma el análisis de los otros materiales del contexto nos sugiere que podría tratarse de una característica propia de algunas de las ocupaciones de estos tiempos más tardíos (debido por ejemplo a relaciones sociales o flexibilización de los códigos decorativos), ya que las diferencias van más allá de la cerámica, involucrando también el contexto lítico, las pipas, los adornos y la subsistencia. Dichas características no presentan similitudes con Llolleo.

Al igual que en el sitio El Almendral, la ocupación de La Palma presenta importantes frecuencias de materias primas de grano fino, apuntando a que estamos frente a contextos líticos tecnológicamente orientados a la reducción bifacial con un claro referente en los instrumentos registrados en sus contextos, especialmente puntas de proyectil ${ }^{18}$. Sin embargo, presenta una situación inédita en sitios del PAT, debido a la importante frecuencia de obsidiana (27,4\%), la cual ingresó al contexto del sitio a través de matrices tipo lascas. Cabe destacar que las fuentes de este recurso se encuentran en la alta cordillera de los Andes en el Cajón del Maipo y en el cajón del río Tinguiririca (Tagle 1996). De hecho, gran parte de la categoría punta de proyectil en el sitio está representada por esta materia prima. Esta situación apunta a que la población que generó el sitio La Palma tuvo un importante acceso a recursos de cordillera a través de un mecanismo no documentado. Sin embargo, la evidencia arqueológica de esta zona, principalmente de la cuenca del río Maipo, solamente ha mostrado un sitio con una frecuencia importante de obsidiana (Los Queltehues) (Luis Cornejo comunicación personal 2002). Refuerza esta situación la presencia de turquesa en el contexto a través de un fragmento de cuenta de collar, situación única de este sitio.

Este sitio presenta además un inédito registro arqueofaunístico de Lama guanicoe que configura un claro patrón de caza con acarreo de unidades de alto rendimiento y abandono de aquellas de baja utilidad en los lugares de caza, con aprovechamiento de recursos faunísticos de diversos microambientes (Velásquez 2000).

En relación a las pipas, éstas tienen características particulares, no observadas en otros contextos: 20 fragmentos muestran que los tubos y los hornillos son de paredes extremadamente delgadas (2-3 mm), y al menos seis tubos tienen un extremo cerrado. Dentro de éstos llaman particularmente la atención los tubos circulares que terminan en un extremo cerrado de sección subrectangular, con una forma en planta en dos puntas (cola de pescado), y un fragmento de pipa de mango achatado, corto y cerrado (Figura 4).

Es interesante también la existencia de una colección de tembetás de tipo tarugo en materias primas silíceas proveniente del área donde se encuentra el sitio. Si bien no se recuperaron ejemplares de este tipo en excavación, su posible asociación a este contexto podría marcar otra diferencia con los otros contextos de la unidad.

\section{Pancho Pistolas y El Mercurio-I}

El sitio Pancho Pistolas RML 001 y la primera ocupación de El Mercurio (EM-I) presentan ciertas características similares entre sí, que los diferencian de los otros analizados. Sin embargo creemos que la información aún es muy escasa como para permitirnos proponer una unidad arqueológica propiamente tal. Por un lado se trata de sólo dos sitios, que además cuentan con un contexto relativamente pequeño dado la escasa magnitud de las excavaciones realizadas. Por otro lado, su rango temporal introduce la variable cronológica como un factor a considerar en relación a las diferencias que observamos entre ambos contextos (150-370 d.C. El Mercurio-I y 435-620 d.C. Pancho Pistolas).

No obstante, creemos que las diferencias que muestran con las otras unidades definidas a nivel de la tecnología (en la alfarería) son relevantes a la variabilidad dentro de este período. Por lo tanto, si bien no podemos hacer una adecuada caracterización, creemos que es importante hacer presente la diferencia.

El principal factor compartido por estas dos ocupaciones es la presencia de las familias de pastas U y M (Tabla 3); aunque la importancia de ellas en ambos sitios no es la misma, es el principal 


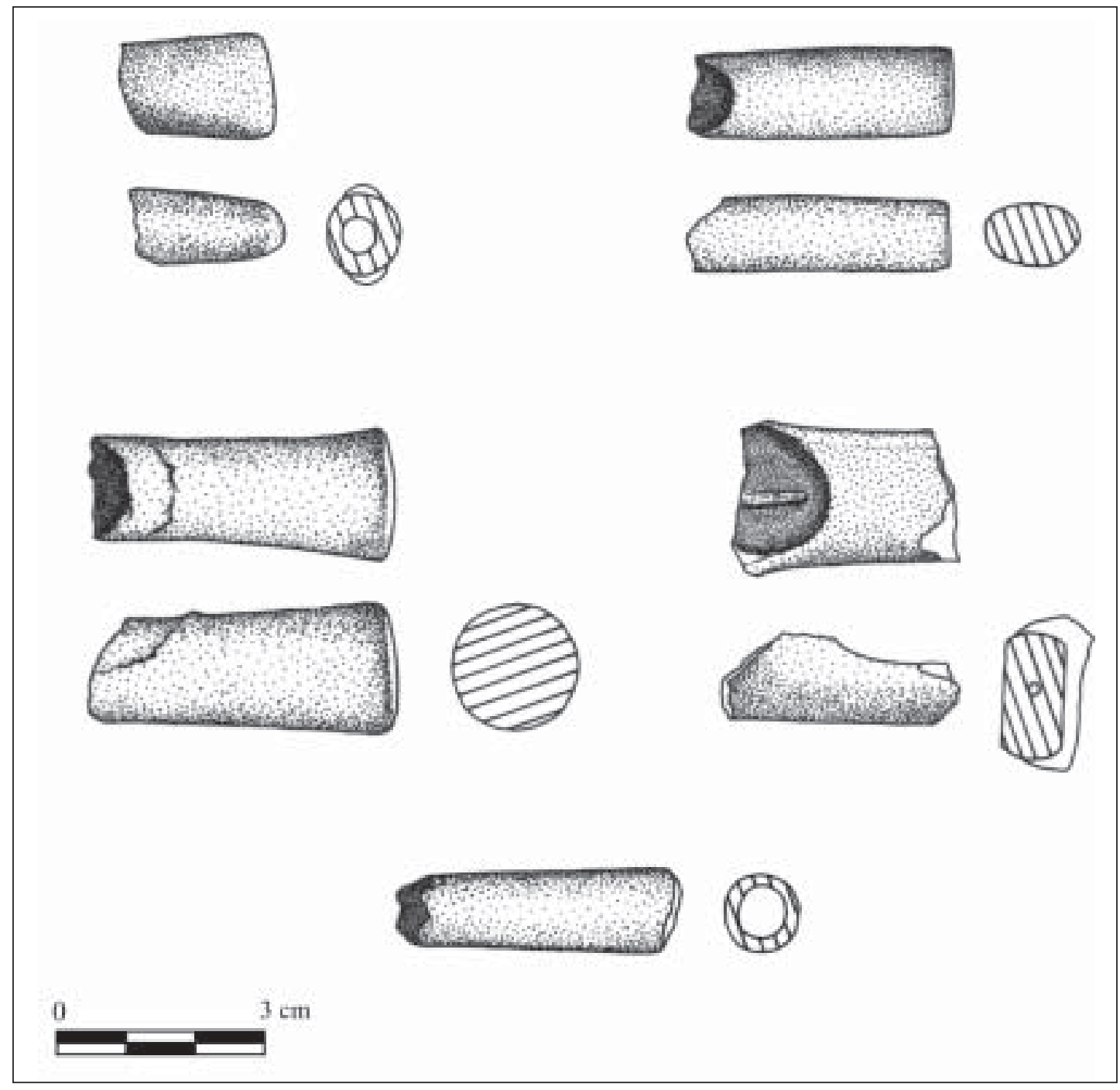

Figura 4. Pipas Complejo Bato, sitio La Palma E101/1.

Bato Complex pipes, La Palma E101/1 site.

elemento que permite establecer una oposición con las otras unidades. Los otros aspectos de la cerámica no permiten establecer asociaciones tan claras y, además, muchos de ellos son compartidos con otras unidades.

En relación al material lítico, y al igual que la cerámica, la escasez de material en el componente EM-I y los problemas de muestra en RML 001, no ha permitido sustentar el reconocimiento de esta situación dentro del PAT.

Necesitamos una muestra mayor de materiales de estos dos sitios y un mayor número de sitios con estas características para poder evaluar de manera adecuada cada una de las variables y las semejanzas que presentan con las otras unidades definidas. Por ahora, sólo podemos constatar que estos sitios contribuyen a la variabilidad del PAT, al no ajustarse a las características de las unidades propuestas.

\section{Chacayes $^{19}$}

Si bien esta unidad sólo está representada en un sitio, las evidencias a partir del material analizado son suficientemente sólidas como para permitir la definición de una unidad a partir de él. Sus 
características ya han sido descritas en detalle en otro trabajo (Sanhueza 2000), por lo que aquí sólo presentaremos una síntesis de los elementos más relevantes y que justifican la definición de una unidad arqueológica diferente.

La tradición tecnológica, vista a partir del análisis de pastas, evidencia una correlación absoluta entre categorías morfológicas y pastas. Es decir, hay tres tipos de vasijas, que se manufacturan con tres tipos de pastas diferentes: las ollas alisadas, las vasijas pulidas y las vasijas decoradas, lo que constituye una diferencia notoria respecto a las otras unidades donde, si bien se pueden ver tendencias de asociación pasta-categoría de vasija, no se pueden establecer relaciones exclusivas.

Las formas de las ollas alisadas se asemejan a las descritas para otras unidades, pero las vasijas pulidas muestran una variedad formal mayor (vasijas simétricas de cuello largo y corto, vasijas asimétricas con uno o dos golletes, eventualmente uno de ellos cribado y vasijas tipo calabaza (lagenarias) $^{20}$. Las decoraciones características son la pintura roja y el negativo, siendo significativa la ausencia de los incisos, tan propios de los otros desarrollos del PAT en Chile central ${ }^{21}$.

En este contexto hay tembetás del tipo discoidal con alas y orejeras hechas en piedra y cerámica. Uno de los enterratorios recuperados presentaba como ofrenda un brazalete y una placa triangular de cobre nativo laminado, lo que nos evidencia el manejo de estos materiales por parte de estos grupos.

En cuanto al material lítico, éste ha sido definido como un contexto de caza asociado a un contexto de molienda similar para el definido en las Comunidades Alfareras Iniciales. Sin embargo, y en relación a los contextos líticos asignados a otras unidades del PAT, este sitio presenta un rasgo especial debido a la importante frecuencia de la categoría "piedras horadadas", las cuales artefactualmente provienen de la retoma de manos de moler discoidales planas, situación única en contextos líticos de la cuenca.

Respecto al patrón de funebria, es poco lo que sabemos, ya que la mayoría de los enterratorios fueron recuperados antes de que los arqueólogos llegaran al sitio. No obstante, al haberse recuperado cerca de 20 entierros (Stehberg 1978) sabemos que se trata de un área de funebria localizada cerca del área de vivienda, con enterratorios asociados a ofrendas de vasijas cerámicas completas principalmente, y también ajuar compuesto de tembetás, orejeras y los mencionados objetos de cobre. $\mathrm{Si}$ bien esta unidad presenta algunas semejanzas evidentes con los contextos Bato, destacan más las semejanzas (sobre todo formales) que presenta con las evidencias Molle del río Hurtado (Irribarren 1958).

\section{Reevaluación de las unidades Bato y Llolleo}

Las unidades Bato y Llolleo aparecen como las unidades más 'coherentes'. Se han reconocido varios sitios para cada una de ellas y presentan una extensión temporal significativa. Si bien en este trabajo las unidades fueron definidas a partir de la tecnología cerámica de pastas, lo que marca una diferencia sustancial respecto a la definición de estas unidades para la costa, es a partir de las asociaciones recurrentes entre cierta tecnología y ciertas formas y decoraciones (además de otros elementos de los contextos) que podemos establecer relaciones entre ellas. En este sentido, las unidades Bato y Llolleo costeras muestran las mismas asociaciones y oposiciones en términos de forma y decoración que las observadas en las unidades del interior.

Lamentablemente no contamos con información acerca de la tecnología de producción de vasijas en todos los sitios de los grupos Bato y Llolleo costeros, y ciertamente las semejanzas en forma y decoración con sus pares del interior no posibilitan extender esta similitud al patrón tecnológico.

En el caso del sitio Llolleo costero LEP-C, los patrones de pasta muestran características completamente diferentes a las pastas de la familia U, propias tanto del sitio EM como de los otros conjuntos alfareros Llolleo del interior conocidos. Mientras los áridos que componen las pastas del sitio costero son de origen granítico (cuarzos, feldespatos, piroxenos), los áridos de las familia $\mathrm{U}$ son de origen volcánico (andesitas, basalto). Estos resultados, aunque parciales y de limitado alcance por estar la costa representada por un solo sitio, nos indican que la geología local está jugando un papel preponderante en la característica de las pastas utilizadas para la fabricación de las vasijas dentro de este complejo. Esto es coherente con resultados de estudios comparativos anteriores, a base de análisis de composición de elementos, entre el 
sitio LEP-C y EM (Falabella et al. 1995-96) en los que se determinó una procedencia diferenciada, probablemente local, de las vasijas.

En el caso de los fragmentos decorados con hierro oligisto (en su variante "pasta gruesa"), en cambio, la situación es diferente. Tanto en LEP-C como en El Mercurio las pastas de los fragmentos con esta decoración, bajo la lupa, son prácticamente iguales. El análisis de composición de elementos concluyó, por su parte, que en ambos casos este tipo de pasta se diferenciaba claramente de la utilizada para confeccionar otro tipo de vasijas, aunque éstas no eran equivalentes químicamente entre sí. Esto muestra que si bien no existía un "centro productor" de este tipo de vasijas decoradas, sí había una "idea común", compartida por los grupos Llolleo, acerca de las características que debían tener las pastas de esta categoría especial de vasija.

Además de la cerámica, otros aspectos son compartidos entre las respectivas unidades de la costa e interior. Uno muy relevante es el patrón de funebria, donde los escasos datos con que contamos en el interior (El Mercurio y G16/1-8/9) se corresponden con las características que adoptan sus pares en la costa. Si bien existen ciertos elementos propios de cada sitio (como por ejemplo las acumulaciones de piedra y la posición sedente en EM-II), existen ciertas constantes en relación a la posición de los individuos y la ofrenda (todos aspectos del ritual mortuorio) en ambas áreas. En Llolleo las urnas asociadas a los infantes ${ }^{22}$, la posición flectada decúbito lateral para los más adultos, las ofrendas cerámicas y los collares son los factores comunes. En Bato, la posición decúbito ventral con las extremidades inferiores hiperflectadas hacia atrás, identificada también en los sitios Trébol SE y Cancha de Golf de la localidad de Quintay (Rivas y Ocampo 1997) y la ausencia de ofrendas cerámicas son los elementos más característicos y compartidos.

Vemos, entonces, que los elementos comunes entre las unidades Bato y Llolleo del interior y la costa van más allá de similitudes meramente formales, incluyendo también aspectos tradicionales e ideológicos, lo que nos habla de un grado de integración que no podemos desconocer y que aún no alcanzamos a entender a cabalidad.

Un dato importante en este sentido es aportado por el análisis de composición de elementos realizado en restos óseos de poblaciones costeras y del interior de la unidad Llolleo (LEP-C y EMII), que dan información sobre su dieta (Falabella et al. 1995-96). Los resultados de los análisis mostraron una concentración diferencial de los elementos zinc $(\mathrm{Zn})$ y estroncio $(\mathrm{Sr})$ para las poblaciones costeras versus interior, lo que fue interpretado como una diferenciación sustancial en la dieta de estas dos poblaciones. Los altos valores de $\mathrm{Zn}$ en las poblaciones del interior podrían estar respondiendo al consumo de cultígenos (legumbres y maíz), mientras que los valores preponderantes de Sr en la costa estarían representando una dieta basada fuertemente en el consumo de mariscos (Falabella et al. 1995-96: 37).

Estos datos, junto con los referidos a la tecnología cerámica, sugieren para el caso Llolleo poblaciones que habitan la mayor parte del año ya sea en la costa o en el interior. Esto no descarta eventuales contactos esporádicos entre los grupos costeros y del interior, en situaciones o contextos donde se actualizarían los lazos entre estos grupos que compartirían una idea común, lo que habría facilitado una similitud en la exterioridad de su cultura material y que nos permite a partir de ello reconocerlos como una conjunto significativo.

Si bien no contamos con información que nos aporte en este sentido para el caso Bato, creemos que la situación no puede haber sido muy diferente a la arriba expuesta.

Creemos que ambas unidades, considerando sus manifestaciones interiores y costeras, responden bien a la definición de 'complejo cultural'. Llolleo fue definido de esta forma desde un principio (Falabella y Planella 1979). Bato, sin embargo, fue definida en un principio como una Tradición (Planella y Falabella 1987). Creemos que los datos proporcionados y la discusión llevada a cabo permiten proponer que el concepto de complejo cultural es aplicable de igual manera a Bato.

No obstante ambos puedan ser considerados como un complejo cultural, sugerimos que Bato y Llolleo son complejos de naturaleza diferente. Proponemos en este sentido al Complejo Bato como representativo de una sociedad de fuerte tradición cazadora recolectora, más móvil y menos homogénea que Llolleo, la cual visualizamos como una sociedad más homogénea, sedentaria y ligada a un modo de vida hortícola.

Creemos que los sitios Bato, aun los más tardíos dentro de la secuencia, muestran que la caza es una actividad de importancia dentro de estos 
grupos, lo que se ve a través de las características de material lítico y los abundantes restos de fauna (principalmente guanaco) en uno de los sitios del interior (E101/1). Esta apreciación ya se tenía a partir de los sitios Bato de la costa, donde la gran abundancia de puntas junto con la presencia de camélidos y otáridos llevaron a plantear que la caza era una actividad importante dentro de estos grupos (Falabella y Stehberg 1989; Planella y Falabella 1987). A diferencia de ellos los sitios Llolleo, especialmente de la cuenca Maipo/Mapocho, no presentan evidencias que permitan pensar que la caza fuera un elemento importante dentro de su subsistencia. En el sitio El Mercurio, por ejemplo, prácticamente no hay puntas de proyectil y en la costa, la cantidad de puntas es menor a la asociada a los sitio Bato.

En este mismo sentido, otra diferencia notable entre Bato y Llolleo se da respecto a la forma de procesar los recursos vegetales. En Llolleo, especialmente en el interior, el procesamiento de vegetales es una actividad importante que se lleva a cabo en morteros cóncavos con canal de molienda definido y asociado a una serie de instrumental lítico utilizado en la reactivación de estos artefactos. En Bato, en cambio, el instrumental de molienda no es sólo menos frecuente, sino que tiene una morfología diferente (mortero plano y mano discoidal plana), lo que implica no sólo un mecánica diferente en el proceso de molienda del vegetal sino tiene directa implicancia en la cantidad de vegetal procesado. Pensamos que esto se relaciona directamente con la importancia de los vegetales procesados en la subsistencia de estos dos grupos, la cual sería mayor para Llolleo.

Otro aspecto en el que se presentan diferencias que sustentan nuestras proposiciones es respecto a la cerámica. Si bien no podemos evaluar en toda su amplitud la tecnología de producción de ésta, la información obtenida por nosotros a partir del análisis en los sitios del interior nos muestra que la tecnología de producción en Llolleo es más homogénea que en Bato. Si bien en ambos complejos existen familias de pastas preponderantes diferentes, que permiten establecer diferencias entre ambos, en Llolleo la familia de pastas características (U) siempre es la más importante, mientras que en Bato ésta (A), si bien se presenta en todos los sitios analizados, siempre está asociada a otras pastas que alcanzan importancias similares o incluso mayores que ésta. Creemos que dado el sistema de producción de la cerámica durante esta época, no especializado y con transmisión del conocimiento artesanal en la familia, condición que debería ser similar en ambos complejos, una mayor o menos homogeneidad en las pastas se relaciona con un sentido de normatividad, que un grupo está expresando más que el otro. Esto puede relacionarse tanto con un idea más acotada y "obligatoria" de cómo deben hacerse las vasijas, como con una mayor interacción entre las unidades donde se produce la cerámica en Llolleo. Por otro lado, tampoco podemos descartar que esta mayor heterogeneidad en Bato pueda deberse a que los sitios representen un mayor número de ocupaciones diferentes por parte de distintos grupos.

No podemos dejar de relacionar esto con el rol que está jugando la alfarería en general en estas dos sociedades, que al parecer es diferente. El hecho de que ésta se utilice comúnmente como ofrenda funeraria y especialmente como urna en Llolleo, plantea una oposición respecto a Bato, donde esto no ocurre. Creemos que la relación de la alfarería con este ámbito importante del ritual le otorga una connotación y un rol absolutamente diferentes en ambas sociedades, la cual también debería estar ligada a la homogeneidad o heterogeneidad de su fabricación.

Por último, existen evidentes diferencias entre estas dos unidades respecto a los adornos corporales utilizados. En Llolleo, las evidencias de funebria y de basurales nos permiten proponer el uso de collares en la vida diaria de estos grupos. En Bato, en cambio, y si bien su uso no es exclusivo de estas sociedades, el tembetá es el "adorno" personal de mayor relevancia (identificable por nosotros). $\mathrm{Si}$ bien es difícil imaginarlo cumpliendo otra función que no sea la de hacer algo muy evidente, no hemos podido encontrar alguna regularidad que nos permita explorar sus contenidos culturales.

\section{Conclusiones}

El Período Alfarero Temprano que se configura a partir de las evidencias presentadas es bastante más complejo y diverso de lo que se vislumbraba hasta ahora. En este panorama tenemos diferentes grupos productores de alfarería que ocupan conjuntamente la costa y el valle y que en la cordillera comparten además el espacio con grupos de tradición de caza y recolección portadores de cerámica (Cornejo y Sanhueza 2003). Estos gru- 
pos, al menos por un tiempo, son contemporáneos, ya que algunos desaparecen y otros se modifican durante el largo tramo temporal del PAT. En este sentido, el PAT debe ser considerado como un proceso dinámico y diverso, en el cual la subsistencia, movilidad y relaciones inter e intragrupales sufrieron modificaciones a lo largo de un milenio.

La aparición de la cerámica en los contextos arqueológicos marca el inicio del PAT en Chile central ( $\mathrm{y}$ en otros lugares). Tradicionalmente se han manejado algunos supuestos relacionados a este fenómeno: la subsistencia basada en la agricultura y un consecuente patrón de asentamiento de mayor sedentarismo (Willey y Phillips 1958). Estudios más recientes en el marco de la 'ecología cerámica' (Arnold 1985) también han subrayado la relación cerámica/sedentarismo/agricultura. No obstante lo anterior, numerosos ejemplos arqueológicos han llevado a flexibilizar esta relación, en la medida que han ido mostrando que estos procesos no siempre se dan en forma paralela (Gebauer 1995; Skibo y Blinman 1999).

La información con que contamos en este momento para Chile central también nos obliga a revisar estos supuestos. Por una parte, los datos no permiten por ahora plantear una aparición de los cultígenos anterior o simultánea de la alfarería. Los primeros indicios de alfarería datan de 800 a.C., aunque no es hasta hacia los 300 a.C. que ésta se populariza. Datos posibles acerca de la presencia de cultígenos no hay hasta 100 a.C., y su presencia no es segura en todos los contextos; no es hasta el 600 d.C. (sitio La Granja) que contamos con evidencia concreta del manejo de un conjunto de ellos: quínoa (Chenopodium quinoa), poroto (Phaseolus vulgaris) y zapallo (Lagenaria sp. y Cucurbita sp. (Planella y Tagle 1998) ${ }^{23}$. Por otra, tampoco estamos en condiciones de evaluar la importancia de los cultígenos en la subsistencia de estos grupos, ya que como se ha podido ver en otros casos (Price et al. 1995), la mera presencia de cultígenos no puede interpretarse como una subsistencia basada en la horticultura ${ }^{24}$.

No contamos con datos que permitan zanjar de manera directa este importante problema, pero la evidencia de las ocupaciones estudiadas por nosotros nos muestran al menos que la caza y la recolección no perdieron su importancia en este período, ni entre las comunidades alfareras iniciales, ni en el complejo Bato. Creemos, por lo tanto, que la aparición de la cerámica en Chile central no implicó necesariamente la incorporación de cultígenos como base de la subsistencia en un principio, y que en tiempos posteriores los distintos grupos/unidades arqueológicas fueron incorporándolos de distintas maneras, de acuerdo a parámetros particulares, de manera que en algunos grupos/unidades éstos pueden haber sido más relevantes que en otros.

El sedentarismo era una implicancia necesaria del modo de vida hortícola supuesto, pero dadas las condiciones expuestas, el cambio de vida desde una movilidad propia de cazadores recolectores hacia el sedentarismo es un proceso que debe haberse dado en forma paulatina, lenta y diferencial, y que no necesariamente todos los grupos vivieron con la misma intensidad.

Respecto a patrones de movilidad, posibles de expresarse en el patrón de asentamiento, no hemos podido encontrar diferencias, ni diacrónicas ni entre grupos a partir de nuestras investigaciones. Los escasos sitios fechados y la dificultad de asignación cultural de los sitios registrados exclusivamente a partir de recolecciones superficiales fueron factores limitantes. No obstante, el hecho que de los sitios excavados y/o estudiados por nosotros la mayoría sean Bato (y que este proceso de selección no fuera "dirigido"), nos sugiere que existen en la cuenca una mayor cantidad de sitios Bato, que podría ser interpretado como reflejo de una sociedad con patrones de movilidad mayores que la Llolleo. En todo caso, lo único claro es que la dispersión de sitios del PAT muestra una localización preferencial cerca de cursos de agua pequeños y aguadas naturales, que se traducen en zonas lagunares y pantanosas, que abundaban anteriormente en la cuenca, lo que configura un paisaje interdigitado, correspondiente a parámetros de territorialidad diferentes a los que manejamos hoy en día.

Respecto a las dinámicas sociales, creemos que las diferencias observadas en la cerámica en el momento posterior al de las Comunidades Iniciales corresponden a la expresión material de procesos de complejización de la organización social. Las redes de relaciones se establecerían no sólo bajo formas como el matrimonio, sino también relaciones de subsistencia y de cooperación, donde sería considerado necesario pertenecer a un grupo y exteriorizarlo en oposición a otros. 
En casos registrados a partir de la etnografía (Jones 1997) se ha podido ver que estos procesos de identificación grupal no son estables, sino que se gatillan o intensifican a partir de determinados estímulos, generalmente relacionados con problemas que pueden ser resueltos sólo a partir de una agrupación mayor. Cuando la necesidad pasa, los niveles de identificación disminuyen, aunque pueden ser reactivados. No tenemos herramientas aún para identificar estas fluctuaciones dentro del PAT, aunque el momento tardío de la secuencia Bato es sugerente porque se observa una desconfiguración de los elementos propios en la decoración de la cerámica, lo que podría deberse a la disminución en la circulación de la información ${ }^{25}$.

En suma, desde una perspectiva diacrónica, por una parte se consolida y configura más claramente un momento temprano (de comunidades alfareras iniciales) tanto en el interior como en la costa; por otra, con los fechados tardíos de Lonquén, E101/1 y El Mercurio, el PAT se extiende de manera clara hasta los inicios del PIT. Los fechados cada vez más tardíos para contextos del PAT han generado un traslape de fechas, aunque debemos destacar que a pesar de esto en ninguna de estas ocupaciones hemos podido observar un proceso de transformación o transición hacia la cultura Aconcagua, y no nos ha permitido avanzar en la comprensión de este cambio tan radical.
Durante este largo período de tiempo las diferencias observadas en la cultura material de los grupos pertenecientes al período alfarero temprano en Chile central no se ordenan fundamentalmente por la cronología. Si bien este factor parece ser relevante en algunos momentos de la secuencia (en especial en los inicios y final del PAT), es cada vez más evidente que la heterogeneidad de manifestaciones que se encuentra a lo largo de este período también tiene una fuerte base social y cultural, que nos muestran un panorama social interdigitado y complejo que apenas hemos comenzado a comprender.

Agradecimientos: Este trabajo se realizó con el apoyo del proyecto Fondecyt 1970910. Comprometen nuestra gratitud las personas que participaron en el trabajo de laboratorio: Daniela Baudet, Cristina Prieto y Gabriela Urízar, colaboraron en el análisis cerámico; José Castelletti y Marcela Becerra colaboraron en el análisis lítico; Carolina Belmar y Luciana Quiroz realizaron los análisis arqueobotánicos y Héctor Velásquez los análisis de fauna. También agradecemos a los investigadores e instituciones que facilitaron el acceso a las colecciones revisadas para este trabajo: C. Thomas, A. Benavente, R. Sánchez, R. Stehberg, Museo Nacional de Historia Natural, Departamento de Antropología de la Universidad de Chile.

\section{Referencias Citadas}

Adams, J.

1999 Refocusing the role of food grinding tools as correlates for subsistence strategies in the U.S. Southwest. American Antiquity 64:475-98.

Arnold, D.

1985 Ceramic Technology and Cultural Process. Cambridge University Press.

Belmar, C. y L. Quiroz.

1999 Informe Flotación: sitios Hospital y Radio Estación Naval. Informe de Avance, Proyecto Fondecyt 1970910. Manuscrito en posesión de Fondecyt.

2000 Informe Flotación: sitios La Palma y Lonquén. Informe Final, Proyecto Fondecyt 1970910. Manuscrito en posesión de Fondecyt.

Berdichewsky, B.

1964 Informe preliminar de las excavaciones arqueológicas en Con-Con. Antropología. Año 2, Vol. 2 (1):65-86.

Cornejo, L.

2000 Asentamiento del complejo Aconcagua en El Manzano: estudios en un sitio agónico. Segundo Taller de Arqueo- logía de Chile Central (1994), http://members. tripod.cl/ lcbmchap/lcb.htm.

Cornejo, L. y L. Sanhueza.

2003 Cazadores recolectores tardíos en la cordillera de Chile central. Latin American Antiquity, en prensa.

Cornejo, L. y P. Galarce

2000 Avances en el estudio de la lítica de las sociedades tardías de Chile central. Actas XV Congreso Nacional de Arqueología Chilena, en prensa.

Cornejo, L., P. Miranda y M. Saavedra

1997 Cabeza de León ¿Una localidad de explotación minera prehispánica en la cordillera Andina de Chile Central? Chungara. 29: 7-18.

Falabella, F.

2000 El sitio arqueológico de El Mercurio en el contexto de la problemática cultural del período alfarero temprano en Chile central. Segundo Taller de Arqueología de Chile Central (1994) http://members.tripod.cl/lcbmchap/lcb.htm.

Falabella, F., E. Aspillaga, R. Morales, M. I. Dinator y F. Llona 1995-1996 Nuevos antecedentes sobre los sistemas cultura- 
les en Chile central sobre la base de análisis de composición de elementos. Revista Chilena de Antropología 13: 29-60.

Falabella, F. y M. T. Planella

1979 Curso Inferior del Río Maipo: Evidencias Agroalfareras. Departamento de Antropología, Tesis de grado, Universidad de Chile.

1988-1989 Alfarería temprana en Chile central: un modelo de interpretación. Paleoetnológica 5:41-64.

Falabella, F. y R. Stehberg

1989 Los inicios del desarrollo agrícola y alfarero: zona central (300 a.C. a 900 d.C.). En Prehistoria de Chile, Desde sus Orígenes hasta Los Albores de la Conquista, editado por J. Hidalgo, V. Schiappacasse, H. Niemeyer, C. Aldunate y I. Solimano, pp. 295-311. Editorial Andrés Bello, Santiago.

Gebauer, A.B.

1995 Pottery production and the introduction of agriculture in Southern Scandinavia. En The Emergence of Pottery. Technology and Innovation in Ancient Societies, editado por W.K. Barnett y J.W. Hoopes, pp. 99-112. Smithsonian Institution Press, Washington.

Iribarren, J.

1958 Nuevos hallazgos arqueológicos en el cementerio indígena de La Turquía-Hurtado. Arqueología Chilena 4:13-40.

Jones, S.

1997 The Archaeology of Ethnicity. Routledge, London.

Kaltwasser, J., A. Medina y J. Munizaga

1980 Cementerio del período Arcaico en Cuchipuy. Revista Chilena de Antropología 3:109-23.

Oyarzún, A.

1979 Los kjoekkenmoeddinger de las costas de Melipilla y Casablanca. En Aureliano Oyarzún N. Estudios Antropológicos y Arqueológicos, editado por M. Orellana, pp. 4557. Editorial Universitaria, Santiago.

Planella, M. T. y F. Falabella

1987 Nuevas perspectivas en torno al Período Alfarero Temprano en Chile central. Clava 3:43-110.

Planella, M. T., F. Falabella y B. Tagle

1996 Fundamentos prehispánicos de la población "promaucae" histórica. Resultados de investigación arqueológica de La Granja, años 1994 y 1995. Informe Parcial Proyecto Fondecyt N ${ }^{\circ}$ 194-0457. Manuscrito en posesión de Fondecyt.

1997 Fundamentos prehispánicos de la población "promaucae" histórica. Informe Final Proyecto Fondecyt $\mathrm{N}^{\mathrm{T}}$ 194-0457. Manuscrito en posesión de Fondecyt.

2000 Complejo fumatorio del período agroalfarero temprano en Chile central. Contribución Arqueológica 5, Tomo I: 895-909.

Planella, M. T. y B. Tagle

1998 El sitio agroalfarero temprano de La Granja: un aporte desde la perspectiva arqueobotánica. Publicación Ocasional Museo Nacional Historia Nacional 52.

2000 Los períodos Arcaico y Agroalfarero Temprano como materia de estudio en la revisión de los inicios de la presencia de cultígenos en la zona central de Chile. Actas $X V$ Congreso Nacional de Arqueología Chilena, en prensa.

Price, T. D., A. B. Gebauer y L. H. Keeley

1995 The spread of farming into Europe north of the Alps. En Last Hunters, First Farmers, editado por T. D. Price y
A. B. Gebauer, pp. 95-126. School of American Research Press, Santa Fe, Nuevo Mexico.

Reyes, O.

1998 Informe antropológico-físico de los restos óseos humanos hallados en la localidad de Hospital. Informe de Avance Proyecto Fondecyt 1970910. Manuscrito en posesión de Fondecyt.

Rice, P. M.

1987 Pottery Analysis: a Sourcebook. University of Chicago Press, Chicago.

Rivas, P. y C. Ocampo

1997 Informe preliminar de las excavaciones de salvataje y de la inspección arqueológica en el fundo Santa Augusta de Quintay, V región. Actas Segundo Congreso Chileno de Antropología, Tomo II: 818-35.

Sanhueza, L.

1997 Relaciones Llano-cordillera Durante el Período Agroalfarero Temprano en Chile Central: una Visión desde la Cerámica. Tesis de Grado. Departamento de Antropología, Universidad de Chile.

2000 Período Alfarero Temprano en Chile central: una visión desde la cerámica. Contribución Arqueológica 5, Tomo II: 541-70.

Sanhueza, L. y F. Falabella 1999-2000 Las comunidades alfareras iniciales en Chile central. Revista Chilena de Antropología 15:29-47.

Sanhueza, L., F. Falabella y M. Vásquez

2000 Reevaluando la presencia de la tradición Bato en el interior de Chile central. Actas Tercer Congreso Chileno de Antropología. Tomo I: 430-439.

Schaedel, R., B. Berdichewsky, G. Figueroa y E. Salas 1954-1956 Manuscrito sobre arqueología de la costa central. Manuscrito en posesión del Museo Nacional de Historia Natural, Santiago.

Silva, J.

1964 Investigaciones arqueológicas en la costa de la zona central de Chile, una síntesis cronológica. Arqueología de Chile Central y Áreas Vecinas, III Congreso Internacional de Arqueología Chilena, 263-273. Santiago.

Skibo, J. y E. Blinman

1999 Exploring the origins of pottery on the Colorado Plateau. En Pottery and People, editado por J. Skibo y G. Feinman, pp. 171-183. The University of Utah Press, Salt Lake City.

Solé, L.

1991 Informe bio-antropológico sitio El Mercurio. Manuscrito en posesión de los autores.

Stehberg, R.

1976 Un sitio alfarero temprano en el interior de la Quinta Normal, Santiago datado en 180 años a.C. Homenaje al Dr. Gustavo Le Paige S.J., editado por H. Niemeyer, pp.12740. Universidad del Norte, Antofagasta.

1978 El cementerio alfarero temprano de Chacayes, interior del Cajón del Maipo, Chile, datado en 430 años d.C. Actas del IV Congreso de Arqueología Argentina, San Rafael, Revista de Historia Natural San Rafael 3 (1/4): 277-95.

Tagle, B.

1996 Análisis del material lítico del sitio La Granja. Informe parcial Proyecto Fondecyt No 194-0457. Manuscrito en posesión de Fondecyt. 
Thomas, C., A. Benavente, C. Massone, N. Gaete, R. Sánchez, G. Serracino, D. Jackson, C. Becker, J., C. Hagn, F. Constantinescu y R. Isaurieta

1990 Arqueología de la comuna de Lampa. Informe Fondecyt $\mathrm{N}^{\circ} 124088$ (Segunda etapa). Manuscrito en posesión de Fondecyt.

Thomas, C., A. Benavente y A. Durán

1980 Análisis crítico comparativo del cementerio Parque La Quintrala, La Reina. Revista Chilena de Antropología 3: 41-56.

Thomas, C. y P. Tudela

1985 El sitio Parque La Quintrala: fechados y seriación. Zona Central de Chile. Actas del IX Congreso de Arqueología Chilena, La Serena: 351-64.

Vásquez, M., L. Sanhueza y F. Falabella

1999 Nuevos fechados para el período Agroalfarero Tem- prano en la cuenca de Santiago: Presentación y discusión. Boletín Sociedad Chilena de Arqueología 28:9-18.

Vásquez, M.

2000 Síntesis Lítica. Informe Final Proyecto Fondecyt 1970910. Manuscrito en posesión de Fondecyt.

Velásquez, $\mathrm{H}$.

2000 Informe análisis arqueofauna sitio E101/1 (La Palma). Informe Final Proyecto Fondecyt 1970910. Manuscrito en posesión de Fondecyt.

Vera, $\mathrm{H}$.

1998 El Manzano 1: Tecnología de puntas de proyectil en la precordillera de Chile central. Manuscrito en posesión de los autores.

Willey G. y P. Phillips

1958 Method and Theory in American Archaeology. University of Chicago Press.

\section{Notas}

1 Los sitios Llolleo conocidos en la costa no se distanciaban más de $40 \mathrm{~km}$; los Bato, en cambio, se dispersaban a lo largo de unos $150 \mathrm{~km}$. El factor distancia puede haber influido en la percepción de mayor homogeneidad y regularidad del conjunto Llolleo.

2 Las áreas seleccionadas para prospección fueron elegidas por medio de un muestreo sistemático no alineado.

3 Por hallazgos aislados entendemos unidades de materiales cerámicos o líticos que no presentan asociación con otros materiales, y que por tanto, consideramos no constituyen evidencia clara de una ocupación propiamente tal. Este tipo de hallazgos es bastante común en la cuenca.

4 Las recolecciones superficiales intensivas se realizaron por transectos distanciados entre sí cada $25 \mathrm{~m}$.

5 Si bien ese sentido estaba en las propuestas originales, el tiempo fue haciéndolas cada vez más rígidas y cerradas.

6 Datum SAM56.

7 El sitio cuenta con otro fechado de $425 \pm 100$ d.C., que corresponde a los estratos superiores (superficie) y que no tiene relación con los materiales aquí discutidos (Vásquez et al. 1999).

8 Hacia los dos primeros siglos de nuestra era, algunas de estas comunidades podrían ser contemporáneas con los inicios de los desarrollos posteriores.

9 Un 10\% en Lonquén y un 16,2\% en Radio Estación Naval.

10 El análisis de huellas de uso de estos instrumentos indica que ambas facetas son utilizadas para la molienda. El registro de pulimento y direccionalidad en las estrías determinó que las manos del sitio REN presentan dos áreas o facetas de desgaste en sus caras activas características del uso sobre morteros plano-cóncavos (Adams 1999).

11 En la primera ocupación del sitio Lonquén se identificó una posible quínoa (Chenopodium quinoa) con banda de cultivo. Sin embargo la semilla se encuentra fragmentada, por lo que su identificación como tal no es segura.

12 Una configuración específica dentro de estas bandas es una banda al pastillaje situada en la unión del cuello con el cuerpo de vasijas restringidas con cuello, con una hilera de incisiones subcirculares. Esta ha sido identificada especial- mente en los sitios de la precordillera y cordillera de Chile central, pertenecientes tanto a los alfareros horticultores como a los cazadores recolectores portadores de cerámica, por lo que ha sido interpretada como relacionada con la interacción de estos grupos en este espacio (Cornejo y Sanhueza 2003).

13 También hay vasijas incisas sin mamelones en las asas, y vasijas sin decoración incisa con mamelones incisos en las asas, pero son menos frecuentes.

14 Hay que recordar que los puntos de inflexión son mucho más difíciles de identificar que los puntos de esquina en la fragmentería, por lo que su importancia numérica en relación a éstos debe evaluarse teniendo esto en consideración.

15 Más que la presencia hemos considerado su frecuencia porcentual: $8 \%$ en La Palma, $10 \%$ en Lonquén y 16,9\% en RML 002.

16 El sitio Parque La Quintrala tiene 10 enterratorios asociados al depósitos de basuras, sin embargo su asociación con este contexto no es completamente clara (Sanhueza 1997)

17 El sitio El Manzano 2 ha quedado fuera de esta discusión por el problema de mezcla de contexto que presenta con la ocupación Aconcagua, lo que impide evaluar adecuadamente su contexto. El sitio Estero Lampa no cuenta con fechados, por lo que su inclusión en este primer momento está basada en las características de sus materiales.

18 Respecto al material lítico de las otras ocupaciones que se ubican en este momento tardío, la escasez de materiales y la ausencia de instrumentos formatizados impide realizar una caracterización.

19 Para detalles de frecuencias, formas y decoraciones ver Sanhueza $(1997,2000)$.

20 Esta impresión de mayor variedad de formas puede deberse al hecho de que muchas de las piezas están enteras o son reconstruibles en un porcentaje significativo.

21 En Chacayes hay algunos pocos fragmentos incisos (1,8\% de los decorados), sin embargo, éstos han sido interpretados como no pertenecientes al conjunto cerámico propio del sitio (Sanhueza 1997). 
22 Sólo hay un caso adecuadamente documentado respecto a una mujer adulta enterrada en urna en el sitio Tejas Verdes 4 (M.T. Planella, comunicación personal 2002).

23 Hay que tener en cuenta, eso sí, que esta discusión puede estar sesgada por la escasez de estudios arqueobotánicos.

24 Existe un fechado sobre semillas carbonizadas de quinoa (Chenopodium quinoa) de 1400-900 a.C. en el sitio Las
Morrenas ubicado en la alta cordillera del Cajón del Maipo (Planella y Tagle 2000), que todavía no ha sido bien evaluado.

25 Esto debe ser tomado sólo a manera de hipótesis porque recordamos que otra causa mencionada para esto es la mezcla no identificada de contextos culturales diferentes por ser los sitios muy superficiales. 